OPEN ACCESS

Edited by: Anne Fletcher,

Monash University, Australia

Reviewed by:

Giovanna Lombardi,

King's College London,

United Kingdom

Nick David Jones,

University of Birmingham,

United Kingdom

*Correspondence:

Mohammad Afzal Khan

mkhan26@kfshrc.edu.sa

Specialty section:

This article was submitted to

Immunological Tolerance

and Regulation,

a section of the journal

Frontiers in Immunology

Received: 20 December 2017

Accepted: 23 April 2018

Published: 24 May 2018

Citation:

Khan MA, Alanazi F, Ahmed HA

Vater $A$, Assiri $A M$ and Broering DC

(2018) C5a Blockade Increases Regulatory T Cell Numbers and

Protects Against Microvascular Loss

and Epithelial Damage in Mouse

Airway Allografts.

Front. Immunol. 9:1010

doi: 10.3389/fimmu.2018.01010

\section{C5a Blockade Increases Regulatory $T$ Cell Numbers and Protects Against Microvascular Loss and Epithelial Damage in Mouse Airway Allografts}

\author{
Mohammad Afzal Khan ${ }^{1,2 *}$, Fatimah Alanazi ${ }^{1,2}$, Hala Abdalrahman Ahmed ${ }^{1}$, Axel Vater ${ }^{3}$, \\ Abdullah Mohammed Assiri ${ }^{1,4,5}$ and Dieter Clemens Broering ${ }^{2}$ \\ ${ }^{1}$ Comparative Medicine Department, King Faisal Specialist Hospital and Research Centre, Riyadh, Saudi Arabia, ${ }^{2}$ Organ \\ Transplant Centre, King Faisal Specialist Hospital and Research Centre, Riyadh, Saudi Arabia, ${ }^{3}$ Aptarion Biotech AG, Berlin, \\ Germany, ${ }^{4}$ College of Medicine, AlFaisal University, Riyadh, Saudi Arabia, ${ }^{5}$ Institute for Research and Medical Consultations, \\ Imam Abdulrahman Bin Faisal University, Dammam, Saudi Arabia
}

Microvascular injury during acute rejection has been associated with massive infiltration of $\mathrm{CD}^{+} \mathrm{T}$ effector cells, and the formation of complement products (C3a and $\mathrm{C} 5 \mathrm{a}$ ). Regulatory $T$ cells (Tregs) are potent immunosuppressors of the adaptive immune system and have proven sufficient to rescue microvascular impairments. Targeting C5a has been linked with improved microvascular recovery, but its effects on the Treg and T effector balance is less well known. Here, we demonstrate the impact of C5a blockade on Treg induction and microvascular restoration in rejecting mouse airway allografts. BALB/C $\rightarrow$ C57BL/6 allografts were treated with a C5a-neutralizing L-aptamer (10 mg/kg, i.p. at d0 and every second day thereafter), and allografts were serially monitored for Treg infiltration, tissue oxygenation $\left(\mathrm{tpO}_{2}\right)$, microvascular blood flow, and functional microvasculature between donor and recipients during allograft rejection. We demonstrated that C5a blocking significantly leads to enhanced presence of Tregs in the allograft, reinstates donor-recipient functional microvasculature, improves $\mathrm{tpO}_{2}$, microvascular blood flow, and epithelial repair, followed by an upregulation of IL-5, TGF- $\beta$, IL-10 vascular endothelial growth factor, and ANGPT1 gene expression, while it maintained a healthy epithelium and prevented subepithelial collagen deposition at d28 posttransplantation. Together, these data indicate that inhibition of C5a signaling has potential to preserve microvasculature and rescue allograft from a sustained hypoxic/ischemic phase, limits airway tissue remodeling through the induction of Treg-mediated immune tolerance. These findings may be useful in designing anti-C5a therapy in combination with existing immunosuppressive regimens to rescue tissue/ organ rejection.

Keywords: C5a blocking, microvascular reestablishment, Treg induction, immunosuppression, airway allografts

Abbreviations: ANOVA, analysis of variance; BPUs, blood perfusion units; d, day; CR, chronic rejection; FOXP3, forkhead box P3; FITC, fluorescein isothiocyanate; AON-D21, anti-C5a L-aptamer; OTT, orthotopic tracheal transplant; PBS, phosphate buffered saline; PFA, paraformaldehyde; SC, Subcutaneous injection; $\mathrm{tpO}_{2}$, tissue oxygenation; Tregs, regulatory T cells; VEGF, vascular endothelial growth factor. 


\section{INTRODUCTION}

Promoting microvascular integrity supports transplant health and may avoid the onset of chronic rejection (CR) of transplanted lungs. Allograft microvascular injuries have been associated with massive infiltration of $\mathrm{CD} 4^{+} \mathrm{T}$ effector cells and antibodymediated complement activation, which promotes obliteration of microvasculature, airway remodeling, and ultimately CR of transplanted lungs (1-5). During the early phase of inflammation, complement pathways release active complement fragments, C3a, C4a, and C5a. These are potent anaphylatoxins that alter vascular permeability and airway remodeling (6-9). In normal circumstances, the $\mathrm{C} 3$ split product $\mathrm{C} 3 \mathrm{~b}$ plays a central role in generating $\mathrm{C} 5$ convertase to cleave $\mathrm{C} 5$ into the active components $\mathrm{C} 5 \mathrm{a}$ and $\mathrm{C} 5 \mathrm{~b}$. Compared to the other C 3 split product, C3a, C5a is the more potent chemotactic agent, and is recognized by C5aR on a variety of lymphocytes including regulatory $\mathrm{T}$ cells (Tregs) during inflammation, and further binding of $\mathrm{C} 5 \mathrm{a}$ during the inflammatory phase results in shifting of the $\mathrm{T}$ cell response to a Th1-type, promoting effector T cell activation (10) and limiting natural regulatory T cell (nTreg) regulatory activities (11). Of note, C5a, being the most potent anaphylatoxin, is considered the biologically most lethal fragment released during complement activation, and is therefore, regarded as a key target for complement modulation $(12,13)$. Although C5 cleavage generates C5a as well as C5b which forms together with C6, C7, C8 and C9 the lytic terminal Membrane Attack Complex, the clinical outcomes of $\mathrm{C} 5$ deficiency do not differ markedly from those of other terminal component deficiencies (e.g., C6, C7, C8, and C9) suggesting that the absence of $\mathrm{C} 5$ a does not contribute significantly to the clinical aftermath in C5-deficient patients. Therefore, the selective blockade of $\mathrm{C} 5 \mathrm{a}$ promises to be the optimal leverage, so that the normal up- and downstream disease-preventing functions of complement remain intact, and only the harmful activated fragment, the pro-inflammatory anaphylatoxin, is blocked.

$\mathrm{CD} 4{ }^{+} \mathrm{CD} 25^{+} \mathrm{FOXP}^{+}$Tregs were first reported to be crucial for the maintenance of self-tolerance, for immune homeostasis and for protection from autoimmune diseases (14). Forkhead box P3 (FOXP3) is an intracellular marker, which is specifically expressed in regulatory $\mathrm{CD}^{+}{ }^{+} \mathrm{CD} 25^{+}$in the course of differentiation from naïve $\mathrm{CD} 4^{+} \mathrm{T}$ cells. Tregs play a central role in establishing immunological tolerance and suppress autoimmunity $(15,16)$. A number of preclinical and clinical studies highlighted the therapeutic potential of these cells in organ transplantation, but pathological or beneficial effects of Tregs on rejecting allografts are still not very clear $(15,17-23)$.

Regulatory $\mathrm{T}$ cells modulate immune balance and selftolerance through the generation of thymus-derived Tregs and peripheral Treg infiltration, and in the last couple of years, the immunosuppressive property of Treg has been utilized to rescue transplants during rejection (24). $\mathrm{CD}^{+} \mathrm{FOXP}^{+}$peripheral Tregs play a fundamental role in maintaining immunotolerance against mucosal injury and pathogenic alloimmunity. In addition, they facilitate tolerance induction in murine models of solid organ transplantation (3-6). In contrast to thymus-derived Tregs, peripheral Tregs are liable to inflammation-induced reversal into effector $\mathrm{T}$ cells (8), thereby limiting their therapeutic potential in autoimmune diseases. Thymus-derived Tregs are critical regulators of self-tolerance (25) and protect against pathogenic alloimmunity (26), and have been shown to facilitate tolerance induction in murine models of solid organ $(24,27)$ and hematopoietic cell transplantation (28). In general, Tregs are known to be crucial in the maintenance of peripheral immune tolerance, and are the key modulators of the immune reaction during allograft maintenance in a number of transplant models including kidney, cardiac, and post-ischemic neovascularization in hind limb ischemia (29-36).

Previously, we reported that Treg-mediated immunotherapy has potential to preserve the microvasculature of transplanted tracheae and thereby to rescue the allografts from a sustained hypoxic/ischemic phase, which limits airway tissue remodeling $(23,37)$. Our findings demonstrated that Treg reconstitution favored reestablishment of donor-recipient microvasculature as compared to rejecting allografts on all time points studied. Furthermore, this study highlighted an interesting inverse correlation between the duration of microvascular loss (hypoxia/ ischemia) and the presence of Tregs in blood and tissue during rejection episodes, which critically affected inflammationinduced epithelial loss, and subepithelial fibrosis.

It has been shown previously that $\mathrm{C} 3 \mathrm{a}$ and $\mathrm{C} 5 \mathrm{a}$ both activate $\mathrm{T}$ cells and antigen-presenting cells (APC), and that signaling of $\mathrm{C} 3 \mathrm{aR} / \mathrm{C} 5 \mathrm{aR}$ on $\mathrm{T}$ cells and APCs influences $\mathrm{T}$ cell differentiation, expansion and survival of $\mathrm{CD} 4^{+} \mathrm{T}$ helper cells, which suggests that complement deficiency or blockade can potentially attenuate $\mathrm{T}$ cell-mediated autoimmunity ( $\mathrm{T}$ regulatory and $\mathrm{T}$ effector cell balance) and thus delay allograft rejection (38). Thus, blocking and deficiency of both C5a and C5aR have been associated with improved allograft survival $(39,40)$. In addition, expression of and signaling through both $\mathrm{C} 3 \mathrm{aR}$ and $\mathrm{C} 5 \mathrm{aR}$ on nTregs has been reported to inhibit Treg function $(3,41)$, while pharmacological blockade of $\mathrm{C} 5 \mathrm{a}$ has been associated with increased frequency of Tregs in a mouse GvHD model and with increased microvascular and epithelial repair in murine airway allografts $(7,24,42)$. These findings prompted us to investigate a possible relationship between the complement cascade and $\mathrm{T}$ regulatory cells, which when combined may further amplify the regulatory mechanism of tissue recipients. The current study pursued to uncover the novel therapeutic benefits of AON-D21, an L-aptamer binding to $\mathrm{C} 5 \mathrm{a}$ and to the C5a moiety on C5 prior to cleavage into C5a and C5b. AON-D21 therapy led to Treg induction, improvement in microvascular blood flow, and associated tissue repair in an experimental mouse model of orthotopic airway allograft (43), which resembles the airway fibrosis seen in clinical lung transplantation $(1,44)$. Therefore, the key objective was to demonstrate if therapeutic administration of the C5a inhibitor AON-D21 may facilitate microvascular blood flow of allografts through Treg induction and thus promote tissue oxygenation $\left(\mathrm{tpO}_{2}\right)$, and limit fibrosis during rejection. This novel therapeutic strategy of targeting the C5a C5aR-axis during acute rejection episodes may be an effective therapeutic strategy in combination with other immunosuppressive regimens for preventing the development of CR. 


\section{MATERIALS AND METHODS}

\section{Mice}

All mice utilized in this study were originally purchased from the Jackson laboratory (JAX, USA), and later maintained as an original colony in our animal research facility at King Faisal specialist Hospital and Research Center (KFSH\&RC), Riyadh, Kingdom of Saudi Arabia.

\section{C57BL/6}

$\mathrm{C} 57 \mathrm{BL} / 6\left(\mathrm{~B} 6 . \mathrm{H}-2^{\mathrm{b}}\right)$ mice were utilized as recipients of all grafts and as tracheal donors in syngrafts as described below (Table 1).

\section{BALB/C}

$\mathrm{BALB} / \mathrm{c}\left(\mathrm{H}-2^{\mathrm{d}}\right)$ mice were routinely used as allogeneic tracheal donors for the B6 strain in the experimental allogeneic orthotopic trachea transplants. Based on our previously published findings $(7,45,46)$, we selected days $4,8,9,10-14,20$, and 28 for studying microvascular flow and tissue hypoxia in experimental groups (Table 1).

\section{Orthotopic Tracheal Transplant (OTT) Model}

The mouse model of OTT is a well-established experimental model of alloimmune airway transplant rejection $(7,24,43$, 45 , 46). Currently, there are no models which consistently produce and replicate fibrotic remodeling as seen in transplant recipients during the progressive development of CR in terminal bronchioles (47). However, the OTT model is a model of large airway transplantation and successfully replicates the development of fibrotic remodeling that develops to lymphocytic bronchitis, which is a key phase of large airway inflammation that can precede $\mathrm{CR}(1,2,44)$. Anatomically, orthotopic grafts remain exposed to air circulation, which provides a unique respiratory interface between donor-recipients microvascular blood flow after transplantation to favor natural physiological conditions. In addition, the orthotopic position of the graft further provides the preservation of the APC and lymphocyte trafficking pathways, which is very critical for the investigation of ongoing airway alloimmune responses during rejection (43). Based on previous studies, this is the most suitable model to examine donor-recipient microvascular connections, the

TABLE 1 | Experimental groups.

\begin{tabular}{|c|c|c|c|c|}
\hline Donor & Recipient & Treatment & Group purpose & $\begin{array}{c}\text { Assessments } \\
\text { (days) }\end{array}$ \\
\hline C57BL/6 & C57BL/6 & Vehicle & $\begin{array}{l}\text { Vehicle-treated } \\
\text { syngeneic control }\end{array}$ & $\begin{array}{c}4,8-14 \\
20,28\end{array}$ \\
\hline BALB/c & C57BL/6 & Vehicle & $\begin{array}{l}\text { Vehicle-treated } \\
\text { allogeneic control }\end{array}$ & $\begin{array}{c}4,8-14 \\
20,28\end{array}$ \\
\hline BALB/c & C57BL/6 & AON-D21 & C5a inhibition & $\begin{array}{c}4,8-14 \\
20,28\end{array}$ \\
\hline BALB/c & C57BL/6 & $\begin{array}{l}\text { Anti- } \\
\text { CD25 + AON-D21 }\end{array}$ & $\begin{array}{l}\text { Regulatory } \mathrm{T} \text { cell } \\
\text { depletion and } \mathrm{C} 5 \mathrm{a} \\
\text { inhibition }\end{array}$ & 8 \\
\hline
\end{tabular}

Sample size $(n)=4-6$ transplants/time point/experiment (repeats of three experiments). real-time monitoring of blood flow and graft oxygenation during rejection episodes.

\section{Surgical Procedure}

King Faisal specialist Hospital and Research Center Animal Care and Use Committee approved the experimental protocol adopted in this study. C57BL/6 (B6.H-2 ${ }^{\text {b }}$ ) were transplanted under sterile conditions with tracheas from $\mathrm{B} 6$ mice (syngeneic tracheal graft) and $\mathrm{MHC}$-mismatched $\mathrm{BALB} / \mathrm{c}\left(\mathrm{H}-2^{\mathrm{d}}\right)$ mice (allogeneic tracheal graft). 4-6 ring long tracheal segments from $\mathrm{CO}_{2}$ euthanized donor mice were dissected out and used as a grafts. C57BL/6 recipient mice were anesthetized with ketamine $(100 \mathrm{mg} / \mathrm{kg})$ and xylazine $(20 \mathrm{mg} / \mathrm{kg})$, and a short incision was made in the middle neck region, which allowed division of strap muscles and visualization of the entire laryngotracheal complex. Finally, donor and recipient tracheas were connected together with 10-0 nylon suture and the overlying skin was closed with 5-0 silk suture $(43,48)$. All transplanted animals were given postoperative medication Carprofen (dose $5 \mathrm{mg} / \mathrm{kg} \mathrm{SC}$ ) and Zolecin (dose $100 \mathrm{mg} / \mathrm{kg} \mathrm{SC}$ ), and were regularly monitored for any respiratory distress-stridor in the first $24 \mathrm{~h}$ after surgery, and in case of any respiratory distress, the recipients were immediately euthanized by $\mathrm{CO}_{2}$.

\section{Depletion of CD25+ Tregs}

C57BL/6 mice were given i.p. injections of anti-mouse CD25 (clone PC61) from BioXCell, USA $(250 \mu \mathrm{g} /$ day). To get maximum Treg depletion, all mice were treated for at least 7 days prior to the day of transplantation $(24,27,49)$. Treg depletion was confirmed by flow cytometry using CD25 staining on $\mathrm{CD}^{+}{ }^{+} \mathrm{FOXP} 3^{+} \mathrm{T}$ cells.

\section{AON-D21 and Blocking of C5a}

AON-D21 is a PEGylated C5a-binding mixed RNA/DNA L-configured aptamer (50). The molecular weight of the oligonucleotide portion is $13,167 \mathrm{Da}$. PEGylation with Y-shaped $40 \mathrm{kDa}$ methoxy polyethylene glycol is done in order to increase the plasma half-life, mainly by reducing glomerular filtration. Due to its un-natural (mirror image) L-configuration, the aptamer AON-D21 is resistant to nuclease attack in blood (51). AON-D21 originates from the L-aptamer NOX-D19, but has an improved affinity and may be easier to produce because it only consists of 40 nucleotides, whereas NOX-D19 consisted of 44 nucleotides (7). To study the effects of the C5a neutralization, BALB/c $\left(\mathrm{H}-2^{\mathrm{d}}\right) \rightarrow \mathrm{C} 57 \mathrm{BL} / 6\left(\mathrm{H}-2^{\mathrm{b}}\right)$ allografts were given $10 \mathrm{mg} / \mathrm{kg}$, of AON-D21 or vehicle ( $5 \%$ glucose) by i.p. injections on $\mathrm{d} 0$ and every second day thereafter.

\section{Flow Cytometric Analysis}

Blood was collected at selected time points posttransplantation through retro-orbital bleeding and collected in $\mathrm{BD}$ vacutainers. Briefly, lymphocytes were isolated by the Histopaque gradient separation method (52). After centrifugation at $400 \times g$ for $30 \mathrm{~min}$, the buffy coat of lymphocytes was aspirated, and specific Treg markers (CD4, CD25, and FOXP3) were stained with fluorescently labeled rat anti-mouse antibodies, i.e., APC-CD4+ (Clone RM4-5 RUO), PE-Cy7 CD25+ (Clone PC 61 RUO), and PE-conjugated 
FOXP3 $^{+}$(Clone MF23 RUO), respectively, as recommended by BD Pharmingen FOXP3 fixation and permeabilization assay, which specifically flow sort the $\mathrm{CD} 4^{+} \mathrm{CD} 25^{+} \mathrm{FOXP} 3^{+}$Treg subpopulation from mixed lymphocytes in systemic circulation. All were referenced to isotype control mouse IgG1-fluorescein isothiocyanate (FITC) (ab91356, abcam) to determine the background due to nonspecific antibody binding, and $\mathrm{T}$ cells were confirmed with CD4 and CD3 coexpression. Data were recorded at the flow rate of $14 \mu \mathrm{l} / \mathrm{min}$ and a minimum of 500,000 events were collected, and further analyzed through BD Accuri integrated software version C6.

\section{Immunofluorescence Staining}

All rejecting and anti-C5a treated allograft specimens were further examined by immunohistochemical staining for $\mathrm{CD}^{+}{ }^{+} \mathrm{FOXP} 3^{+}$ Tregs in grafts. Briefly, tracheal transplants were harvested and processed in Tissue-Tek O.C.T. medium (Sakura Finetek, Japan). A cryostat (HM550; Microm) was utilized to cut $5 \mu \mathrm{m}$ sections of the tracheal grafts and the sections were placed on superfrost/ plus slides (Fisher Scientific). After fixation in methanol/acetone (1:1) for $10 \mathrm{~min}$ at $-20^{\circ} \mathrm{C}$, the slides were washed with phosphate buffered saline (PBS). Next, graft sections were incubated with $10 \%$ donkey serum for $30 \mathrm{~min}$ and then incubated for $1 \mathrm{~h}$ with either rat anti-mouse CD4 (BD biosciences, USA) or rabbit antimouse FOXP3 (abcam, USA) primary antibodies. The slides were then washed with PBS, and sections were further incubated for $1 \mathrm{~h}$ with Cy3 donkey anti-rat (Jackson Immuno research, USA) and Alexa 647 donkey anti-rabbit (Jackson Immuno research, USA) secondary antibodies. After incubation, sections were washed and mounted in Vectashield mounting medium (Vector Laboratories, USA). Immunofluorescence image analysis was performed with the EVOS FL auto cell imaging system (Life technologies, USA), Five random high-powered fields were captured per slide, and the percentage of colocalization was quantified through the mean integrated fluorescence intensity of the Alexa 488-conjugated secondary antibody used to detect the CD4 antigen, and the Alexa 647-conjugated secondary antibody used to detect FOXP3 deposition per treatment group using ImageJ program $(7,44,46)$.

\section{Assessment of Donor-Recipient Functional Microvasculature}

The donor-recipient functional microvasculature was examined through whole mount graft fixations (46). Briefly, the transplanted and anesthetized mouse was injected with $100 \mu \mathrm{l}$ of $1 \mathrm{mg} / \mathrm{ml}$ FITC-conjugated Lycopersicon esculentum tomato lectin into the inferior vena cava (44). After 5 min of FITC-lectin circulation, the vasculature was flushed with $1 \%$ paraformaldehyde (PFA) via the aorta for $2 \mathrm{~min}$, and the graft was harvested and fixed in $1 \%$ PFA at $4^{\circ} \mathrm{C}$ for $10 \mathrm{~min}$. Next, the graft was mounted and examined by fluorescence microscopy (EVOS FL auto cell imaging system, Life technologies, USA), and morphometric assessment of $\%$ perfused microvasculature was quantified by capturing five random high-powered fields per slide, and the mean integrated fluorescent intensity was calculated per treatment group using ImageJ program $(7,46)$.

\section{Assessment of Graft Oxygenation and Microvascular Blood Flow}

The level of graft oxygenation $\left(\mathrm{tpO}_{2} \mathrm{mmHg}\right.$ ) and blood perfusion units (BPUs) during rejection were measured by combined oxygen and blood flow sensors (model NX-BF/OF/E, Oxford Optronix, UK) as described earlier with some modifications $(7,43,46)$. Briefly, the transplanted mouse was anesthetized, the graft was exposed, a $23-\mathrm{G}$ needle was used to make a hole in the anterior wall, and a combined oxygen and blood flow sensor was inserted at a $<45^{\circ}$ angle to contact the epithelium of the opposite wall of the trachea. The sensor was lowered gradually via the micromanipulator until the $\mathrm{tpO}_{2}$ levels decreases to $5 \mathrm{mmHg}$ or less (indicating a zeroing effect induced by tissue compression). The sensor was then raised in small increments until the $\mathrm{tpO}_{2}$ and $\mathrm{BPU}$ reading plateaus and a consistent reading was obtained. The consistent $\mathrm{pO}_{2}$ was lost as the sensor continues to be lifted off the surface of the airway. The loss of contact of the sensor with the airway epithelium was indicated by a rapid rise to at least $60 \mathrm{mmHg}$ indicating that luminal $\mathrm{pO}_{2}$ (rather than tracheal airway tissue $\mathrm{pO}_{2}$ ) was now being sensed by the sensor, and we typically take multiple readings and average the values $(43,48)$.

\section{Histopathology and Collagen Staining}

To demonstrate subepithelial deposition of collagen, anti-C5a treated and untreated allografts were harvested and processed in Tissue-Tek O.C.T. medium (Sakura Finetek, Japan). A cryostat (HM550; Microm) was utilized to cut $5 \mu \mathrm{m}$ sections of the tracheal graft and the sections were placed on superfrost/plus slides (Fisher Scientific). Next, slides were stained by H\&E and trichrome to detect airway epithelial structures and collagen deposition as described previously (53) and imaged using a Leica light microscope to localize collagen deposition. Morphometric analysis of collagen deposition was quantified by capturing five random high-powered fields per slide, and pixel numbers were converted into micrometers to calculate mean bandwidth $\left(\mu \mathrm{m}^{2}\right)$ per treatment group using ImageJ program $(7,54)$.

\section{Quantitative PCR}

RT-PCR analysis of pro-inflammatory, anti-inflammatory, and angiogenic genes was performed with some modifications (55). Briefly, total RNA from tracheal grafts was extracted using RNeasy mini kit 50 (Qiagen Sciences, MD, USA) and quantified using a NanoDrop 1000 spectrophotometer (NanoDrop Technologies, USA). cDNA from each isolated RNA was synthesized with a high capacity cDNA reverse transcription kit (Applied Biosystems) and real-time PCR was performed using gene-specific primers on an AB 7500 Fast Real-Time PCR system in triplicates (Applied Biosystems) using power SYBR Green (Applied Biosystems). Data were analyzed with integrated software, and expression levels were analyzed by the $2^{-\Delta \Delta C t}$ method after normalization to the housekeeping gene glutaraldehyde dehydrogenase. We selected genes with expected regulatory (IL-10 and TGF- $\beta$ ), Treg induction-specific (IL-5), proangiogenic [vascular endothelial growth factor (VEGF) and ANGPT1], and inflammatory (IL-6) effects. A complete list of individual primers used in the present study is shown in Table 2. 
TABLE 2 | Sequence of primers for RT-PCR analysis.

\begin{tabular}{|c|c|c|}
\hline Gene & Sequence & Refseqs \\
\hline \multirow[t]{2}{*}{ IL-5 } & Forward & TGGGGGTACTGTGGAAATGC \\
\hline & Reverse & CCACACTTCTCTIITGGCGG \\
\hline \multirow[t]{2}{*}{ TGF- $\beta$} & Forward & ACTGGAGTTGTACGGCAGTG \\
\hline & Reverse & GGCTGATCCCGTTGATITCC \\
\hline \multirow[t]{2}{*}{$\mathrm{IL}-10$} & Forward & GTAGAAGTGATGCCCCAGGC \\
\hline & Reverse & GGAGAAATCGATGACAGCGCC \\
\hline \multirow[t]{2}{*}{ VEGF-a } & Forward & TATTCAGCGGACTCACCAGC \\
\hline & Reverse & CTGGGACCACTTGGCATGG \\
\hline \multirow[t]{2}{*}{ ANGPT1 } & Forward & GCTTGGCTTGGATGTGCAAC \\
\hline & Reverse & TTAGTACCTGGGTCTCAACATCTG \\
\hline \multirow[t]{2}{*}{ IL-6 } & Forward & СTCATTCTGСTCTGGAGCCC \\
\hline & Reverse & TGTGACTCCAGCTTATCTCTTGG \\
\hline
\end{tabular}

\section{ELISA}

Quantitative estimation of serum cytokinelevels was performed by Milliplex MAP Mouse Th17 Magnetic Bead (Cat \# MTH17MAG$47 \mathrm{~K})$, briefly, blood was collected in BD vacutainers, incubated at room temperature for at least $30 \mathrm{~min}$, and then processed at 1,200 RCF for $10 \mathrm{~min}$, followed by serum aliquots into cryovials and stored at $-80^{\circ} \mathrm{C}$. As suggested by the manufacturer, samples or standards (6-point dilution) were mixed with antibody-linked magnetic beads on a 96-well plate and incubated overnight at $4^{\circ} \mathrm{C}$ with shaking. Plates were washed twice with wash buffer in a Biotek ELx405 washer. Following a 1-h incubation at room temperature with biotinylated detection antibodies, streptavidin-PE was added for $30 \mathrm{~min}$ with shaking. Plates were washed as above, and PBS added to wells for reading in the Luminex 200 instrument, with a lower limit of 100 beads per sample per cytokine. Each sample was measured in duplicates.

\section{Statistical Analysis}

GraphPad ${ }^{\mathrm{TM}}$ Prism software version 5 was used for statistical analysis to compare treated and untreated groups over time. Differences between various groups at multiple time points were compared using two-way analysis of variance (ANOVA) with post hoc Bonferroni correction for multiple comparisons while results at one time point were analyzed by one-way ANOVA or two-tailed $t$-test and a $p$-value $<0.05$ was considered as significant.

\section{RESULTS}

\section{Blocking C5a is Associated With CD4 ${ }^{+}$CD25 ${ }^{+}{ }^{-O X P 3}{ }^{+}$Treg Increase}

Previously, it was reported that pro-inflammatory activities of C5a regulate adaptive immune responses, and affect the development of Tregs through C5aR signaling, which drives Th1 maturation (56-58). Here, we tested the impact of pharmacological C5a blockade by the L-aptamer AON-D21 on the frequency of Tregs in circulation and in grafts during allograft rejection. AON-D21, an improved form of the specific C5a inhibitor AON-D19, had been reported earlier to promote microvascular recovery and to limit airway remodeling during allograft rejection (7) but its effect on cellular immunity, especially on Tregs had not been investigated.

To assess peripheral and intragraft Treg counts during allograft rejection, we grafted $\mathrm{C} 57 \mathrm{BL} / 6\left(\mathrm{~B} 6, \mathrm{H}-2^{\mathrm{b}}\right)$ with tracheas from $\mathrm{MHC}$-incompatible $\mathrm{BALB} / \mathrm{c}\left(\mathrm{H}-2^{\mathrm{d}}\right)$ donors. Peripheral $\mathrm{CD} 4{ }^{+} \mathrm{CD} 25^{+} \mathrm{FOXP}^{+}$Treg counts were determined in blood lymphocytes collected from untreated BALB/c $\left(\mathrm{H}-2^{\mathrm{d}}\right) \rightarrow \mathrm{C} 57 \mathrm{BL} / 6$ $\left(\mathrm{H}-2^{\mathrm{b}}\right)$ allografts and anti-C5a treated BALB/c $\left(\mathrm{H}-2^{\mathrm{d}}\right) \rightarrow \mathrm{C} 57 \mathrm{BL} / 6$ $\left(\mathrm{H}-2^{\mathrm{b}}\right)$ allografts at $\mathrm{d} 6, \mathrm{~d} 10$, and $\mathrm{d} 14$ posttransplantation. Our initial findings showed that $\mathrm{C} 5 \mathrm{a}$ neutralization leads to elevated levels of $\mathrm{CD}^{+} \mathrm{CD}_{2} 5^{+} \mathrm{FOXP} 3^{+}$Tregs, compared to untreated control allografts at d6 and d10 posttransplantation (Figures 1A-E). These findings indicate that C5a blockade has potential to modulate ongoing inflammation-mediated injuries and consequently to slow down the process of rejection and microvascular injury. Although there was a significant increase in peripheral $\mathrm{CD}^{+}{ }^{+} \mathrm{CD} 25^{+} \mathrm{FOXP}^{+}$Tregs at $\mathrm{d} 6, \mathrm{~d} 10$, and $\mathrm{d} 14$ posttransplantation under $\mathrm{C} 5$ a blockade, the $\mathrm{CD}^{+}{ }^{+} \mathrm{FOXP}^{+} / \mathrm{CD} 4 \mathrm{~T}$ cell ratio in this group was only on days 6 and 10 but not on day 14 lower than in the control group. This was due to a late drop in $\mathrm{CD}^{+} \mathrm{FOXP} 3^{+}$ lymphocytes while significant increase in $\mathrm{CD} 4^{+} \mathrm{T}$ cells occurred.

Because peripheral $\mathrm{CD}^{+} \mathrm{CD}^{2} 5^{+} \mathrm{FOXP} 3^{+}$Tregs have been associated with improvements in donor-recipient microvascular blood flow, we next investigated whether the observed systemic increase in Tregs is also associated with a surge in subepithelial Tregs or drop in number of $\mathrm{CD}^{+} \mathrm{T}$ cells in allograft. We performed immunofluorescent co-staining of anti-C5a-treated allografts for CD4 and FOXP3 at 110 posttransplantation. Immunofluorescence imaging showed an increased subepithelial colocalization of FOXP3 on $\mathrm{CD}^{+} \mathrm{T}$ cells in anti-C5a-treated allografts compared to untreated control allografts, which in previous studies overlapped with the day of microvascular rejection in untreated allografts (Figures 2A-D). The systemic increase in $\mathrm{CD} 4^{+} \mathrm{CD} 25^{+} \mathrm{FOXP} 3^{+}$ Tregs was found to be directly proportional to the increase of intragraft $\mathrm{CD} 4{ }^{+} \mathrm{FOXP} 3^{+}$Tregs, which, we strongly believe will take part in maintaining microvascular repair. This latter observation is consistent with the fact that, in the current trachea transplantation model, subepithelial presence of $\mathrm{CD}^{+} \mathrm{FOXP}^{+}$Tregs is associated with microvascular restoration and tissue repair $(24,27)$.

\section{Blocking C5a Preserve Donor-Recipient Microvasculature, and Improves Graft Oxygenation and Microvascular Blood Flow}

While the effects of $\mathrm{C} 5 \mathrm{a}$ inhibition by the related L-aptamer NOX-D19 on vascular reestablishment, $\mathrm{tpO}_{2}$ blood perfusion had already been reported earlier (7), here we further delineated the effects of the follow-up drug candidate AON-D21 which surprisingly showed Treg induction in treated allografts. This prompted us to further investigate in detail the effects of C5a blockade on donor-recipient microvasculature, graft oxygenation, and microvascular blood flow. As reported previously, Treg induction has been associated with vital improvements in microvascular blood flow, $\mathrm{tpO}_{2}$, and preserved donor-recipient microvascular flow during airway allograft rejection $(24,27)$. Therefore, the purpose of this study was to further study the 


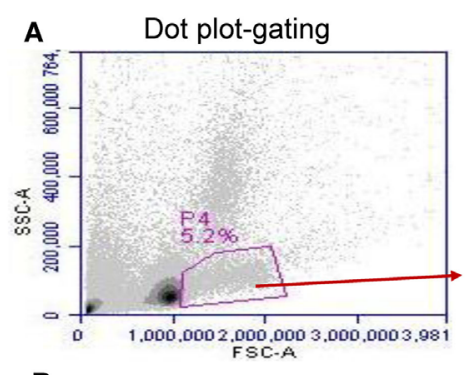

B
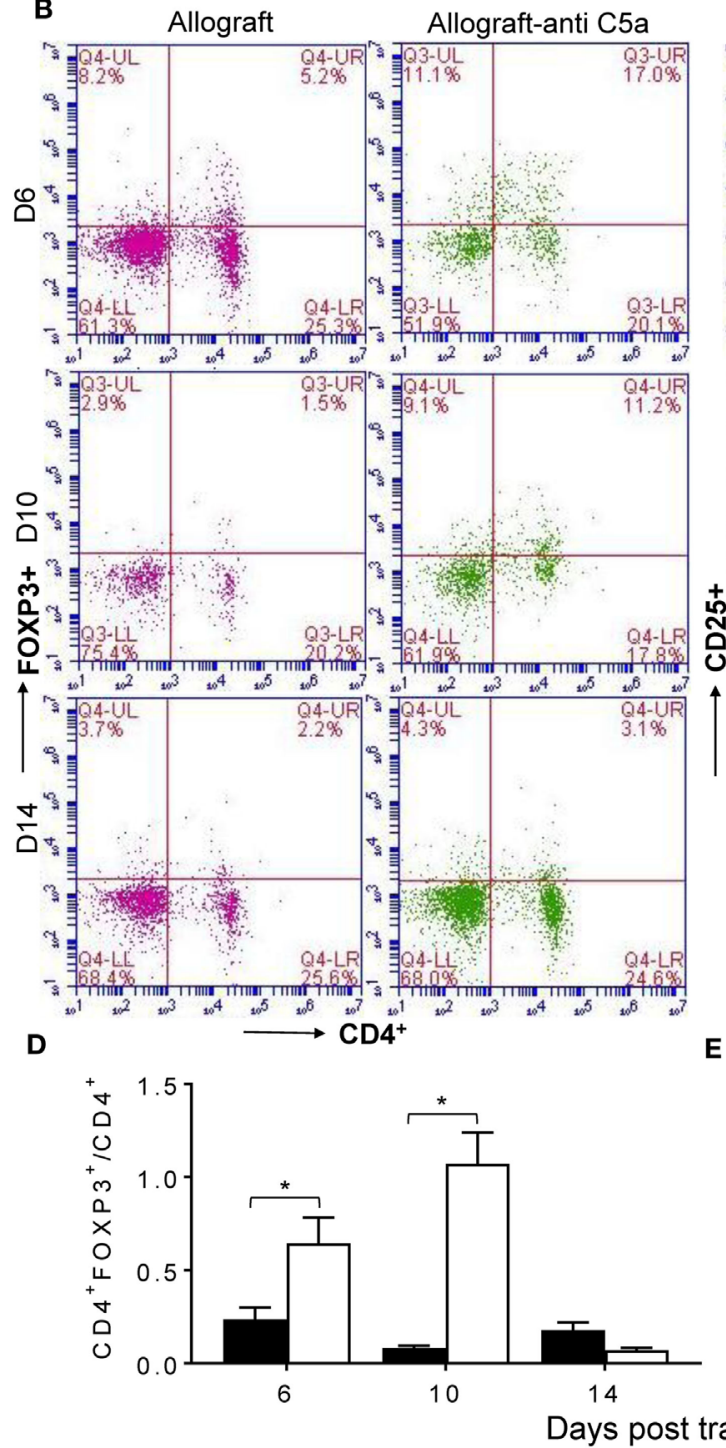

E
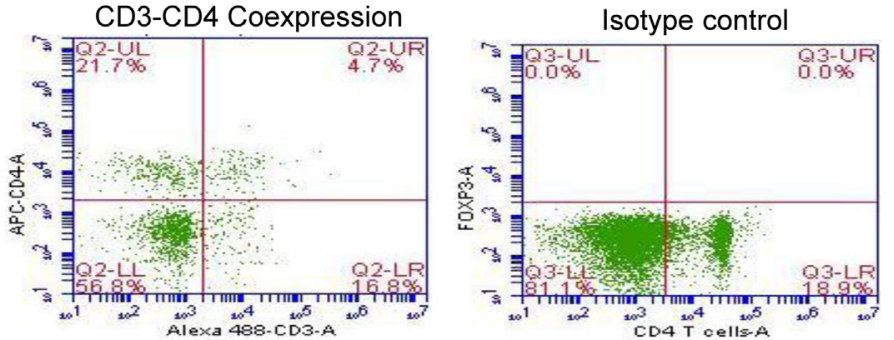

C
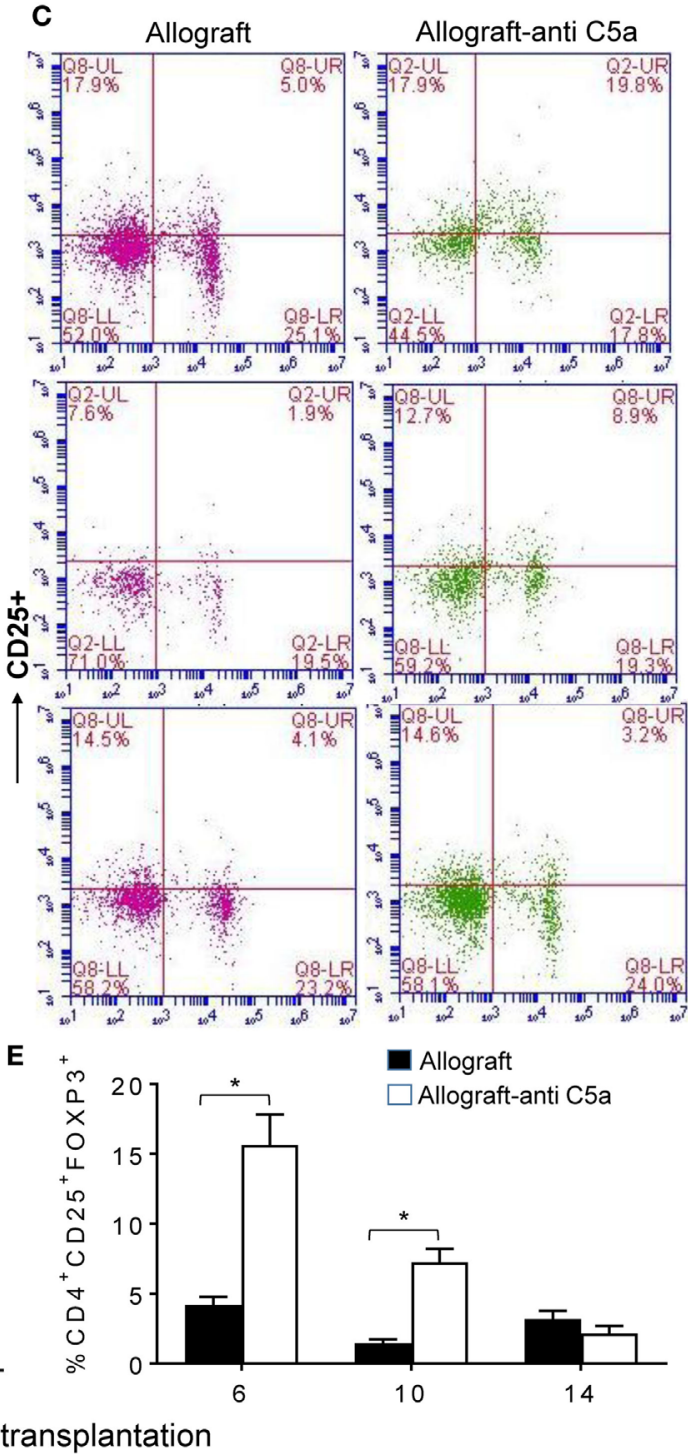

FIGURE 1 | C5a blockade is associated with increased CD4+CD25+FOXP3+ regulatory T cell (Treg) numbers. Flow cytometry analysis of Tregs from peripheral blood of allograft recipients on d6, d10, and d14 posttransplantation: (A) Dot plot displaying SSC/FSC of lymphocytes, CD3 ${ }^{+}$positive CD4+ $4^{+}$lymphocytes, and isotype control analysis. (B) Percentage of CD4+FOXP3+ lymphocytes in peripheral blood. (C) Percentage of CD4+CD25+ lymphocytes in peripheral blood. (D) Ratio of $\mathrm{CD}^{+}{ }^{+} \mathrm{FOXP3}{ }^{+}$to $\mathrm{CD} 4+$ lymphocytes. (E) Percentage of CD4+CD25+FOXP3+ Tregs of peripheral lymphocytes. Data are presented as means with SE of 4-6 transplants/time point/experiment, and repeats of three different experiments. ${ }^{*} p<0.05$.

effects of pharmacological C5a inhibition on $\mathrm{tpO}_{2}$ and blood perfusion during airway allograft rejection. We hypothesized that C5a blockade-mediated Treg induction would reinstate donor-recipient microvasculature, and would thereby ameliorate microvascular flow and $\mathrm{tpO}_{2}$. In this therapeutic protocol, anti-C5a treated and untreated allografts were monitored for 

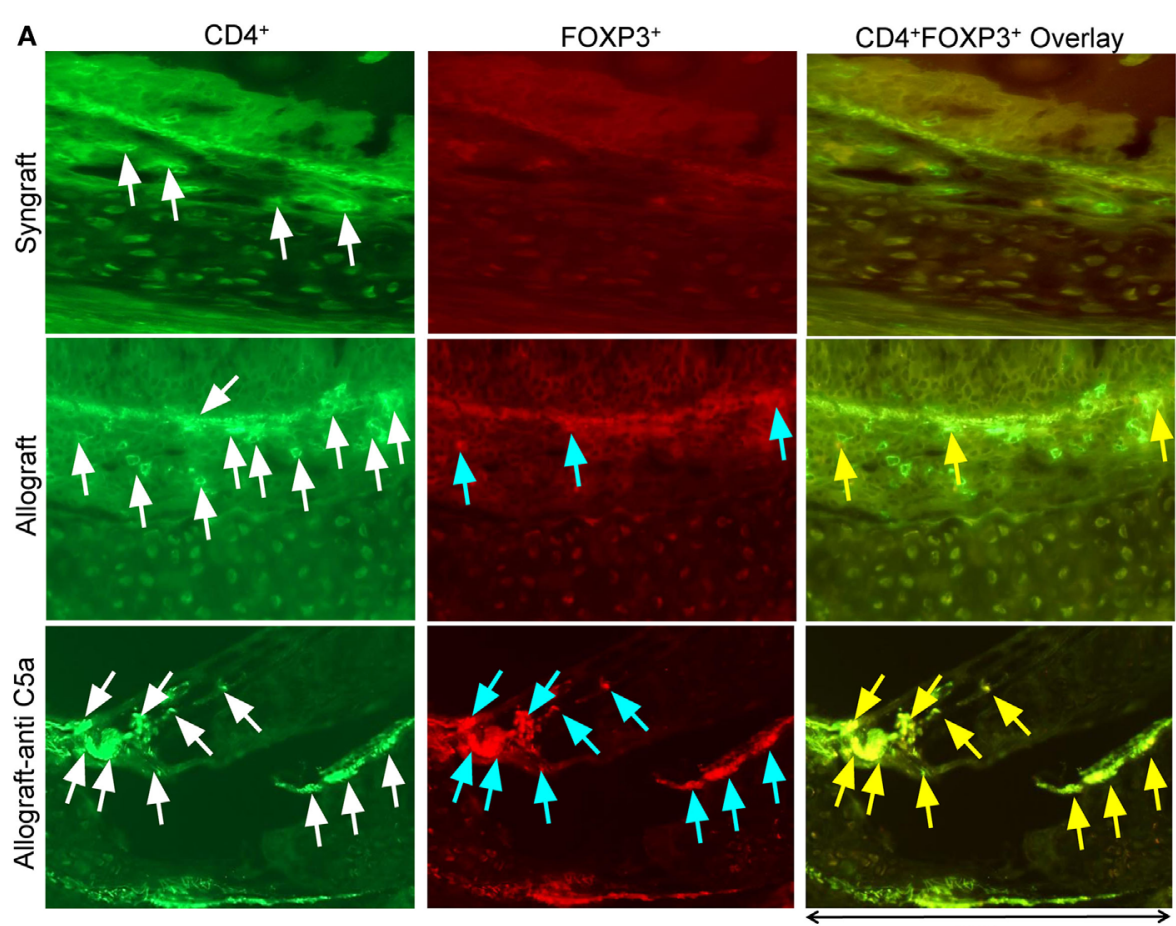

$100 \mu \mathrm{m}$

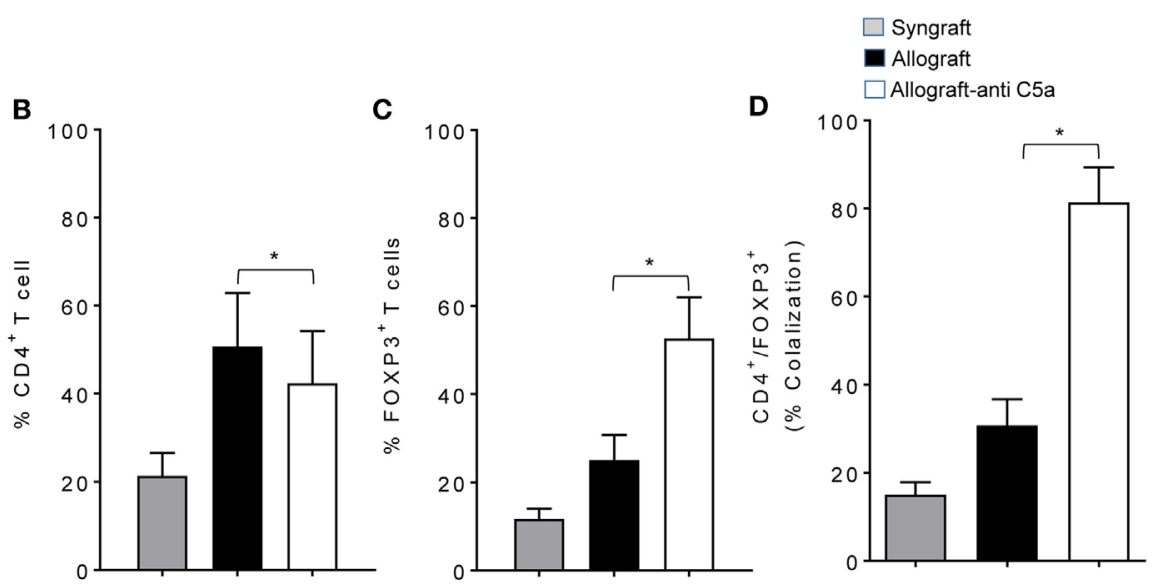

FIGURE 2 | C5a blockade increased infiltration of regulatory T cell (Treg) in allograft. (A) Immunofluorescent staining for CD4 and forkhead box P3 (FOXP3) at d10 posttransplantation. (B-D) Morphometric analysis of graft infiltrating CD4 ${ }^{+} \mathrm{T}$ cells, FOXP3 ${ }^{+}$cells, and $\mathrm{CD} 4^{+} \mathrm{FOXP} 3^{+}$colocalization (Tregs). Arrows highlighted individual $\mathrm{CD}^{+} \mathrm{T}$ cells (white arrows), FOXP3 ${ }^{+}$cells (blue arrows), and CD4+FOXP3 ${ }^{+}$Tregs (yellow arrows). Data are presented as means with SE of 3-4 transplants/time point/experiment, and repeats of three different experiments. ${ }^{*} p<0.05$. Original magnification, $\times 40$.

$\mathrm{tpO}_{2}$, microvascular blood perfusion, and occurrence of donorrecipient microvasculature in the course of airway rejection.

First, to investigate anti-C5a-mediated microvascular reestablishment and associated donor-recipient microvasculature tissue repair in rejecting allografts, we grafted C57BL/6 recipients with tracheas from MHC-incompatible $\mathrm{BALB} / \mathrm{c}$ donors (allografts) or from C57BL/6 donors (syngrafts). To further investigate microvascular recovery, anti-C5a-treated allografts were examined by FITC-lectin binding assay, which specifically detects the pattern of donor-recipient functional microvasculature during rejection $(7,41,46)$. We found that syngrafts remained perfused with high vascular density throughout the period of transplantation. In the allograft setting, anti-C5atreated allografts showed improved microvascular perfusion at $\mathrm{d} 8, \mathrm{~d} 10-\mathrm{d} 13$, and $\mathrm{d} 28$ as compared to untreated control allografts, which lost perfusion and remained poorly perfused with significantly lower vascular density (Figures $3 A$ A,B). These findings support the notion that $\mathrm{C} 5 \mathrm{a}$ neutralization promotes the microvascular reestablishment. Furthermore, these findings supported that enhanced microvascular density in anti-C5atreated allografts may be crucial for maintaining high oxygenation and perfused microvascular state.

To test this, we examined the levels of $\mathrm{tpO}_{2}$ and microvascular blood flow (measured in BPUs) in syngrafts, untreated 


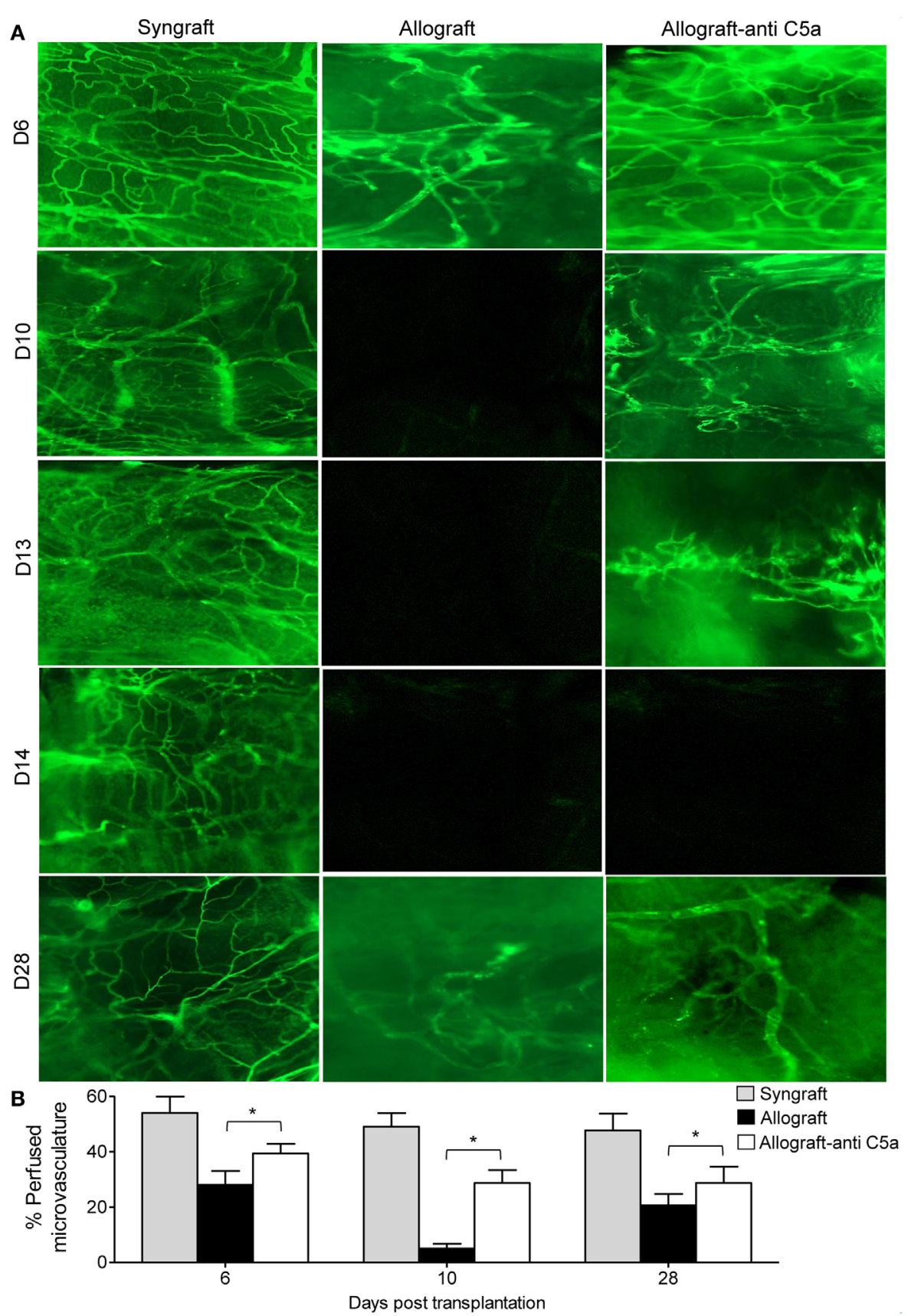

FIGURE 3 | C5a blockade preserves donor-recipient microvasculature. (A) Lectin binding assay of whole mount tracheal grafts on d6, d10, d13, d14, and d28. Original magnification, $\times 20$. (B) Morphometric assessment of perfused vasculature (lectin-stained vessels/unit area) in allo-transplanted groups at different time points. Data are presented as means with SE of 4-6 transplants/time point/experiment, and repeats of three different experiments. ${ }^{*} p<0.05$.

control allografts, and anti-C5a-treated allografts from $\mathrm{d} 4-\mathrm{d} 28$ posttransplantation (Figures 4A,B). Our results demonstrate that $\mathrm{BALB} / \mathrm{c} \rightarrow \mathrm{C} 57 \mathrm{BL} / 6$ untreated control allografts, BALB/ $c \rightarrow$ C57BL/6 anti-C5a-treated allografts, and C57BL/6 $\rightarrow$ C57BL/ 6 syngrafts showed a significant increase $(p<0.05)$ in $\mathrm{tpO}_{2}$ and BPUs after first graft donor-recipients microvascular hookup at $\mathrm{d} 4$, and thereafter all experimental groups remain oxygenated until d8 posttransplantation (Figures 4A,B). At later time points, $\mathrm{C} 57 \mathrm{BL} / 6 \rightarrow \mathrm{C} 57 \mathrm{BL} / 6$ syngrafts remain oxygenated and perfused until $\mathrm{d} 28$ posttransplantation without any sign of donor-recipient microvascular loss and associated ischemia. However, $\mathrm{BALB} / \mathrm{c} \rightarrow \mathrm{C} 57 \mathrm{BL} / 6$ untreated control allografts pass through an extended period of hypoxia and ischemia from $\mathrm{d} 9-\mathrm{d} 14$ and only show a late but inadequate recovery in both $\mathrm{tpO}_{2}$ and blood microvascular perfusion by $\mathrm{d} 28$ posttransplantation (Figures 4A,B). Next, we examined BALB/c $\rightarrow$ C57BL/6 


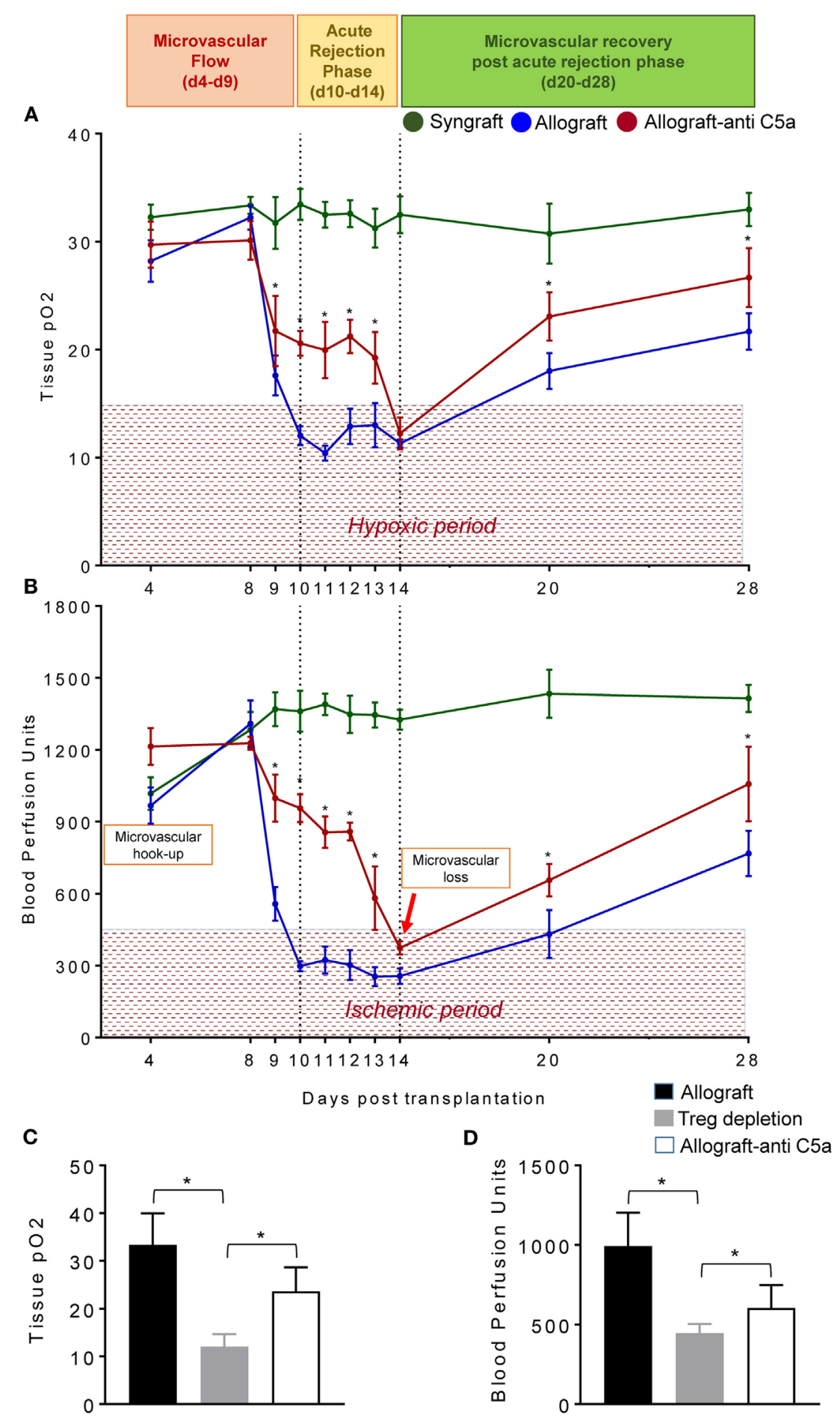

FIGURE 4 | C5a-mediated regulatory T cell (Treg) induction improves tissue $\mathrm{pO}_{2}$, blood perfusion. (A) Tissue $\mathrm{pO}_{2}(\mathrm{mean} \pm \mathrm{SE}, \mathrm{mmHg})$ and (B) blood perfusion (mean \pm SE, units) were plotted over different time points (d4-d28). (C,D) Tissue $\mathrm{pO}_{2}$ and blood perfusion were plotted in untreated, Treg depleted, and antiC5a-treated transplants at d8 posttransplantation. Data are presented as means with SE of 4-6 transplants/time point/experiment, and repeats of three different experiments. ${ }^{*} p<0.05$.

anti-C5a-treated allografts, and our initial findings demonstrated significant improvements both in $\mathrm{tpO}_{2}$ and blood microvascular perfusion leading to a reduced overall hypoxic and ischemic period of anti-C5a-treated allografts. In detail, our data reveal that anti-C5a-treated allografts remain significantly oxygenated (21.72-19.25 $\mathrm{mmHg}$ tpO ${ }_{2}$ ) and perfused (998-581 BPUs) 
at $\mathrm{d} 9-\mathrm{d} 13$ and only showed a brief period of hypoxic/ischemic phase around $\mathrm{d} 14$ followed by a significant and rapid rise of $\mathrm{tpO}_{2}$ and BPUs until d20-d28 posttransplantation (Figures 4A,B). Furthermore, to better understand the mechanism behind the correlation between Tregs, C5a blockade and the microvascular restoration, we first depleted the Tregs with anti-mouse CD25 (clone PC61), and then treated Treg-depleted transplants with the C5a-neutralizing L-aptamer to validate the potential tolerogenic effects of C5a blockade. Our results supported the notion that Treg depletion is associated with a drop in both $\mathrm{tpO}_{2}$ and low blood flow state. In addition, subsequent C5a blockade was found sufficient to recover the tissue oxygen and blood flow at $\mathrm{d} 8$ posttransplantation (Figures 4C,D).

In summary, syngrafts remain oxygenated/perfused from $\mathrm{d} 4$ of microvascular hookup until $\mathrm{d} 28$ of posttransplantation without any sign of microvascular loss at d10/d14 but rejecting allografts pass through a comparatively shorter oxygenated phase from $\mathrm{d} 4$ to $\mathrm{d} 9$ and are progressively hypoxic/ischemic from d10 to d14 posttransplantation, while anti-C5a-treated allografts showed an extended period of graft oxygenation from $\mathrm{d} 4$ to $\mathrm{d} 13$ followed by a reversible microvascular loss at $\mathrm{d} 14$, which confirmed that
anti-C5a-treated allografts enjoyed a longer period of oxygenation and blood microvascular flow, and therefore they pass only through a brief phase of hypoxic and ischemic state compared to untreated allografts (Figures 4A,B). This brief phase of low $\mathrm{tpO}_{2}$ and BPUs in anti-C5a-treated transplants is followed by a rapid rise in $\mathrm{tpO}_{2}$ and $\mathrm{BPUs}$ compared to untreated transplants supported the notion that anti-C5a-mediated Treg induction is involved in microvascular improvements (Figures 4A,B). Of note, anti-CD25-mediated Treg depletion subdued $\mathrm{tpO}_{2}$ and blood flow, while concomitant C5a blockade improved tissue oxygen and blood flow. Collectively, these findings indicate that $\mathrm{C} 5 \mathrm{a}$ blocking delays the onset of acute rejection, and thereby shortens the phase of hypoxia/ischemia as seen in untreated allografts (Figures 4A-D).

\section{Blocking C5a Limits Airway Epithelial Injury and Prevents Collagen Deposition}

Airway epithelial injury and deposition of collagen are the leading pathological events, and key irreversible pathological consequences that proceed when rejecting allografts undergo a

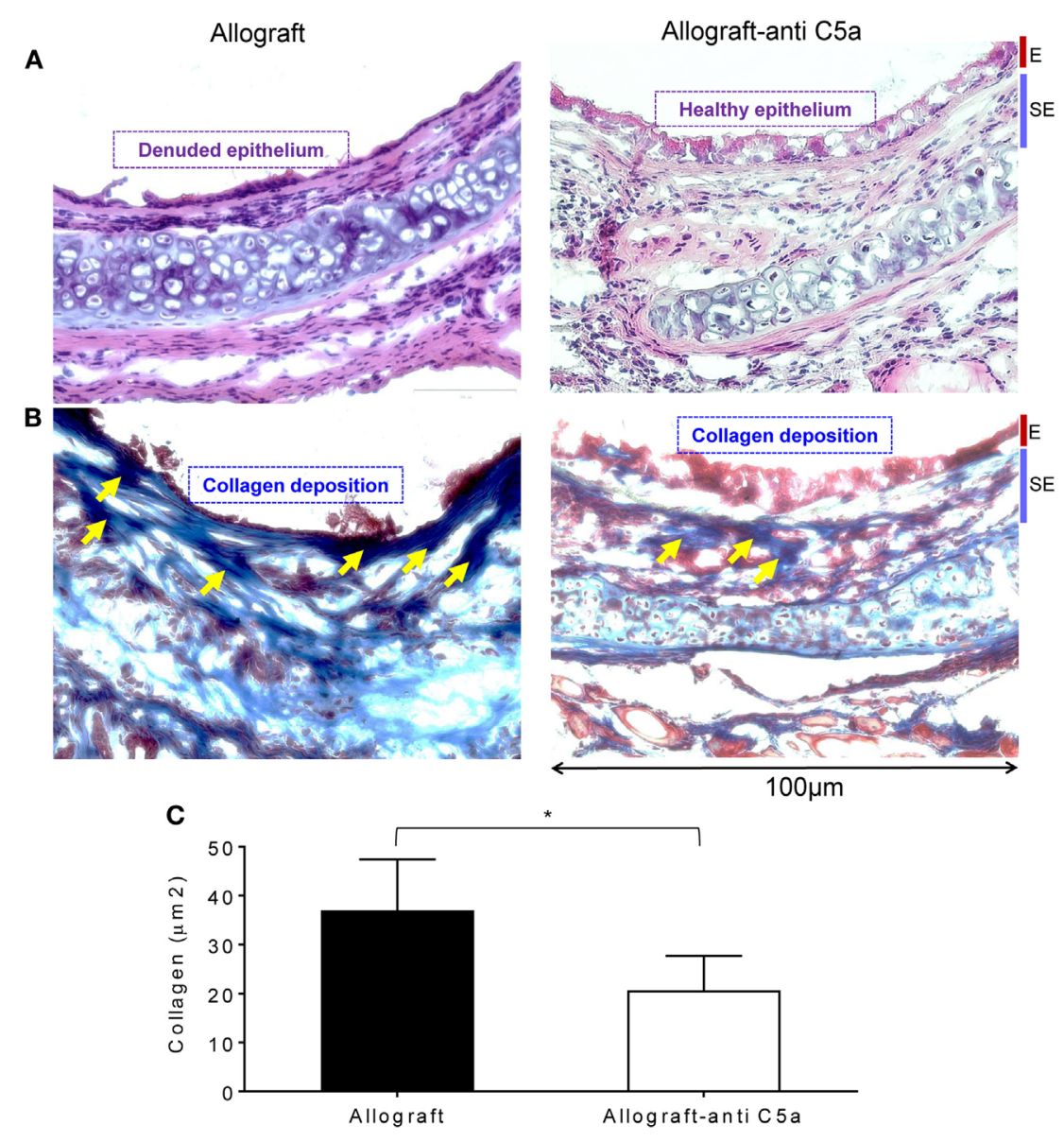

FIGURE 5 | C5a inhibition improves allograft health and prevents collagen deposition. (A) H\&E staining of BALB/c $\rightarrow$ C57BL/6 allotransplants on d28 posttransplantation. (B,C) Subepithelial deposition and quantification of collagen: blue bands represent subepithelial collagen deposition and quantification of collagen blue bands was performed using ImageJ program. "E" and "SE" designate graft epithelial and subepithelial areas, respectively. Data are shown as means with SE and representative images of at least two different experiments $(n=3-4) .{ }^{*} p<0.05$. Original magnification, $\times 40$. 
state of severe hypoxia/ischemia, and ultimately develop fibrotic remodeling during the terminal phase of CR (46). To investigate these pathological changes, we performed $\mathrm{H} \& \mathrm{E}$ and trichrome staining on untreated allografts and anti-C5a-treated experimental groups on $\mathrm{d} 28$ posttransplantation. Microscopic examinations of H\&E demonstrated that $\mathrm{C} 5 \mathrm{a}$ inhibition resulted in healthier epithelium at $\mathrm{d} 28$ as compared to untreated control allografts, which remain denuded and do not show any associated tissue repair/healthy epithelium (Figures 5A). In addition, trichrome staining of anti-C5a-treated allografts showed a significant drop in subepithelial collagen deposition at $\mathrm{d} 28$ compared to untreated control allografts (Figures 5B,C).

\section{Blocking C5a Attenuates Inflammatory Gene Expression While Promotes Regulatory/Proangiogenic Gene \\ Expression}

In order to demonstrate that the beneficial effects of C5a neutralization on microvascular-associated allograft improvements,
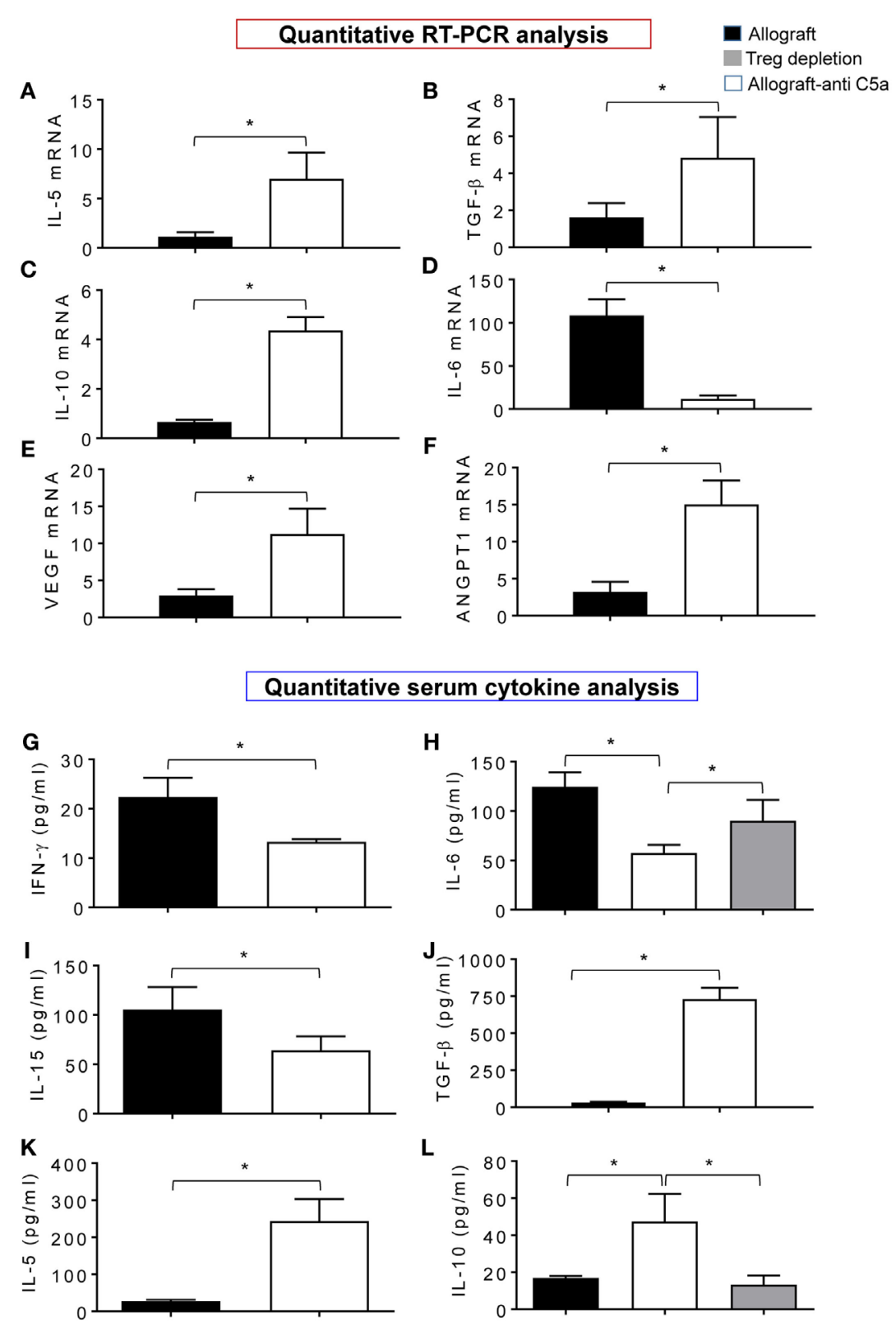

$\mathbf{L}$

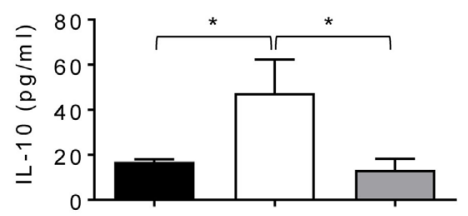

FIGURE 6 | C5a inhibition promotes gene expression and anti-inflammatory cytokine. (A-F) Quantitative RT-PCR analysis shows fold change in regulatory and proangiogenic genes IL-5, TGF- $\beta$, IL-10, IL-6, vascular endothelial growth factor (VEGF), and AGPT1 mRNA at d10 posttransplantation. (G-L) Quantitative analysis of serum cytokines $(\mathrm{pg} / \mathrm{ml})$ at d10 posttransplantation. Data are presented as means with SE of 3-4 transplants/time point/experiment, and repeats of three different experiments. 
we compared the leukocyte gene expression and serum cytokine levels in treated and control allografts. Quantitative PCR analysis revealed that anti-C5a-treated allografts showed a significant increase in mRNA transcript of IL-5, TGF- $\beta$, IL-10, VEGF, and ANGPT1 compared to untreated control allografts (Figures 6AE). In addition, expression of IL-6, which is responsible for tissue-specific inflammation during acute rejection in untreated control allografts, was reduced in anti-C5a-treated allografts (Figure 6F). Figures 6G-L demonstrated a significant drop in levels of IFN- $\gamma$, IL-6, and IL-15, while significant increase in TGF- $\beta$, IL-5, and IL-10 serum cytokine levels in anti-C5a treated allografts. Thus, potential effectors of immunomodulatory activity of C5a blockade are IL-10 and IL-5, which most likely affect the microvascular-associated recoveries during transplantation. We next investigated if pharmacologic C5a blockade promotes expression of gene transcripts relevant for allograft rejection, in anti-C5a-treated allografts and untreated control allografts at d10 posttransplantation. These findings indicate that enhanced microvascular reestablishment in anti-C5a-treated allograft recipients occurred mainly because of turning on of proangiogenic mRNA gene transcripts, which facilitated the process of microvascular reestablishment.

Furthermore, to confirm the cellular source of these proinflammatory cytokines and regulatory cytokines, we collected serum at d10 from Treg-depleted allografts along with control allografts, and quantified IL-10 (regulatory cytokine) and IL-6 (pro-inflammatory cytokine). Our initial data shows that "Tregdepleted" serum samples were found low in IL-10 levels compared to allografts, while IL-6 levels were not affected compared to allograft controls. These data raise the possibility of Tregs as one of the major source of IL-10 as seen in serum from anti-C5a-treated allografts which had more IL-10 than vehicle-treated allografts (Figures 6H,L).

\section{DISCUSSION}

The association between the complement pathway and Tregs has been well reported (59). Tregs play a crucial role in maintaining immune tolerance in both preclinical studies and are also associated with improved long-term transplant outcomes in clinical studies $(60,61)$.

Herein, we tested, whether and how pharmacologic C5a inhibition by the C5a-binding aptamer AON-D21 modulated the peripheral and intragraft numbers of Tregs during orthotopic trachea transplantation. We observed that targeted blocking of C5a signaling augments peripheral $\mathrm{CD} 4^{+} \mathrm{FOXP} 3^{+}$Treg numbers improves microvascular blood flow, and, as a consequence, limits tissue injury and collagen deposition during allograft rejection. The present study was designed to evaluate whether induction of Tregs after complement C5a blockade supports the reestablishment of microvasculature of rejecting allograft and improves $\mathrm{tpO}_{2}$ and blood perfusion. Our results indicate that C5a blockade induces an increase in peripheral $\mathrm{CD} 4{ }^{+} \mathrm{CD} 25^{+} \mathrm{FOXP} 3^{+}$Tregs and within the graft which is accompanied by an upregulation of IL-5, TGF- $\beta$, IL-10, VEGF, and ANGPT1, and reduced IL-6 mRNA gene expression. In additional studies of cytokine concentrations,
C5a blockade led to a significant increase in serum levels of TGF- $\beta$, IL-5, and IL-10, while reduced levels of IFN- $\gamma$, IL-6, and IL-15 were observed. Altogether, this favorable environment seems to contribute to an improved, i.e., anti-inflammatory and more angiogenic balance of the immune system during the allograft microvascular repair, and may help to establish a state of immunotolerance. Earlier, it was demonstrated that blocking/ or genetic deficiency of $\mathrm{C} 3 \mathrm{aR} / \mathrm{C} 5 \mathrm{aR}$ on Tregs enhanced their in vitro and in vivo suppressive activity and prolonged allogeneic skin graft survival (40). Additional studies demonstrated that C3aR/C5aR deficiency/or blockade stimulates murine Tregs, stabilizes FOXP3 gene expression, prevents Treg conversion to IFN- $\gamma / \mathrm{TNF}-\alpha$ producing $\mathrm{T}$ effector cells, and thereby limits graft versus host disease $(59$,$) . Liu et al. reported an antagonistic$ effect between $\mathrm{CD} 4{ }^{+} \mathrm{CD} 25^{-} \mathrm{T}$ cells and $\mathrm{CD} 4^{+} \mathrm{CD} 25^{+}$Tregs on macrophage M1 and M2 polarization, respectively $(62,63)$. In addition, $\mathrm{CD} 25^{\text {high }} \mathrm{FOXP}^{+}$were the dominant cell type which indicated that $\mathrm{C} 5 \mathrm{a}$ inhibition supports the induction of this Treg subgroup, which has stronger immune-suppressive properties than $\mathrm{CD} 25^{\text {low }} \mathrm{FOXP} 3^{+}$Tregs. FOXP3 is the most specific intracellular Treg marker; it is strongly associated with the survival and function of Tregs (64-66). Our results demonstrated that $\mathrm{CD} 4{ }^{+} \mathrm{CD} 25^{+}$cells from treated allograft recipient blood express high levels of FOXP3, whereas FOXP3 and CD25 expression in untreated allograft recipients was considerably lower. Our results also demonstrated that reduced infiltration of $\mathrm{CD}^{+}$effector $\mathrm{T}$ cells in anti-C5a-treated allograft are in agreement with previous findings which supports the notion that $\mathrm{CD} 4{ }^{+} \mathrm{CD} 25^{+} \mathrm{FOXP} 3^{+}$cells are more suppressive (67). BALB/ $\mathrm{c} \rightarrow \mathrm{C} 57 \mathrm{BL} / 6$ allografts exhibited low expression of FOXP3 and $\mathrm{CD} 25$ during allograft rejection and, as expected, low tpO and blood perfusion levels were noted. To check the effect of $\mathrm{C} 5 \mathrm{a}$ neutralization in $\mathrm{BALB} / \mathrm{c} \rightarrow \mathrm{C} 57 \mathrm{BL} / 6$ allografts, we used a novel anti-C5a L-aptamer, AON-D21, and showed that targeted blocking resulted in improved microvascular repair, improved $\mathrm{tpO}_{2}$ and a higher number of peripheral and allograft resident FOXP3 $^{+}$Tregs. In addition, $\mathrm{CD}^{+} \mathrm{T}$ cell-mediated inflammation was limited, suggesting that pharmacologic C5a inhibition triggers the induction of $\mathrm{CD} 25^{+} \mathrm{FOXP}^{+}$Tregs which support the reparative phase of rejecting allograft through microvascular reestablishment. Furthermore, reestablishment of microvascular flow in C5a-treated allografts is highly correlated with the maintenance of normal airway structural recovery which is characterized by relatively low subepithelial fibrosis and healthy ciliated pseudostratified columnar epithelium compared to severely damaged airway epithelium and significantly higher collagen deposition in untreated allografts. Clinical studies from obstructive bronchitis reported that epithelial cell destruction during persistent inflammation occurs due to a variety of inflammatory mediators in small airways, which impede epithelium regeneration and promote fibro-proliferation due to aberrant tissue repair. These epithelial injuries have been recognized as a key intermediate step that is ultimately leading to obliterative airway disease (68-71). In conclusion, we reported that blockage of $\mathrm{C} 5 \mathrm{a}$ triggers activation and expansion of $\mathrm{CD}^{+}{ }^{+} \mathrm{FOXP} 3^{+}$circulating Tregs. The delineation of this formerly uncharacterized mechanism favors the possibility that targeted 


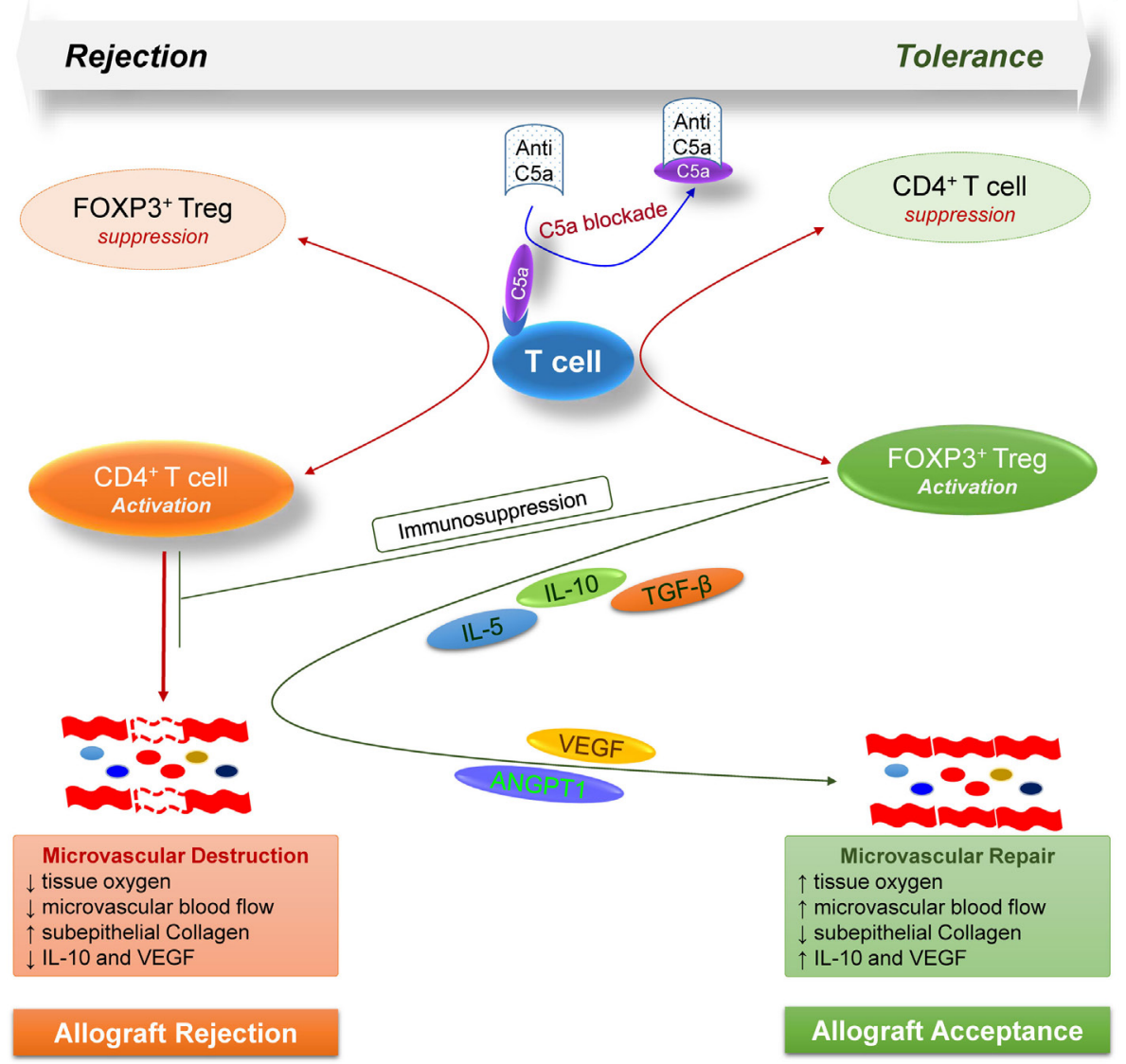

FIGURE 7 | Model illustrates how, during allograft rejection, complement C5a blockade modulates the balance of regulatory and effector T cells, and repairs transplant associated microvascular flow through the release of various regulatory and angiogenic mediators.

blocking of C5a could be exploited to rescue microvascular loss during allograft rejection, and limiting $\mathrm{C} 5 \mathrm{a} / \mathrm{C} 5 \mathrm{aR}$ signaling on Tregs could be used to induce Treg activation and regulatory functions, thereby enhancing Treg responses in allografts. It is known that complement activation and signaling through $\mathrm{C} 3 \mathrm{aR}$ and $\mathrm{C} 5 \mathrm{aR}$ suppress regulatory functions of murine natural regulatory $\mathrm{T}$ cells through FOXP3 expression (11). In addition, immune cell-derived complement also impacts human T-cell immunity and GvHD, highlighting the scope of complement blockade for GvHD treatment $(41,73)$. These preclinical and clinical findings provide proof of concept that C5a blockage is a key target for facilitating Treg-mediated transplant tolerance $(7,72)$. Recently, it was reported that anti-C5a treatment is associated with a decrease of pro-inflammatory chemokines, inhibition of infiltration of neutrophils, and enhanced Th2 response in a murine model of colitis (74). C5a receptors also play a key role in modulating alloreactivity of Tregs which are the main regulatory cell responsible for tissue repair during extensive allograft injury, and mediate tolerance to alloantigens in humans (56). Complement antagonism as a therapeutic alternative or addition necessitates a comprehensive information about the mechanisms of complement activation, cell types, and cell mediators responsible for the inflammation and associated tissue injuries. Various approaches to inhibit the complement system have been tested in preclinical models, particularly in ischemia/reperfusion injury, and in transplantation. Most of the previous investigations had proposed that a successful treatment with a specific complement-inhibitor is the ultimate proof that complement plays an essential role in the pathogenesis of disease.

Taken together, these findings highlight the key modulatory effects of complement on $\mathrm{T}$ cell-mediated alloimmune reactions, and further demonstrate a proof of concept that targeting C5a blockade could facilitate Treg-mediated tolerance to alloantigens (Figure 7). Consequently, the anti-C5a L-aptamer AON-D21 could be exploited to promote induction of immune tolerance to alloantigens in clinical settings as standalone or combination therapy to subdue the severe toxic effects of ongoing immunosuppressive regimens.

\section{AUTHOR CONTRIBUTIONS}

All major experiments, data analysis, and manuscript writing were performed by MK. AV provided AON-D21 and reviewed the manuscript. FA contributed in immunostaining, flow cytometry, 
and PCR. HA contributed in histology and immunofluorescence staining experiments, while AA and DB provided key suggestions during the whole study.

\section{ACKNOWLEDGMENTS}

This research study was approved and financed under the RAC 2150017 to MK (PI) by Office of Research Administration at the King Faisal Specialist Hospital and Research Centre (KFSH\&RC),

\section{REFERENCES}

1. Luckraz H, Goddard M, McNeil K, Atkinson C, Charman SC, Stewart S, et al. Microvascular changes in small airways predispose to obliterative bronchiolitis after lung transplantation. J Heart Lung Transplant (2004) 23:527-31. doi:10.1016/j.healun.2003.07.003

2. Luckraz H, Goddard M, McNeil K, Atkinson C, Sharples LD, Wallwork J. Is obliterative bronchiolitis in lung transplantation associated with microvascular damage to small airways? Ann Thorac Surg (2006) 82:1212-8. doi:10.1016/j. athoracsur.2006.03.070

3. Cravedi P, van der Touw W, Heeger PS. Complement regulation of T-cell alloimmunity. Semin Nephrol (2013) 33:565-74. doi:10.1016/j.semnephrol. 2013.08.007

4. Kwan WH, van der Touw W, Heeger PS. Complement regulation of T cell immunity. Immunol Res (2012) 54:247-53. doi:10.1007/s12026-012-8327-1

5. Mathern DR, Heeger PS. Molecules great and small: the complement system. Clin J Am Soc Nephrol (2015) 10:1636-50. doi:10.2215/CJN.06230614

6. Khan MA, Assiri AM, Broering DC. Complement mediators: key regulators of airway tissue remodeling in asthma. J Transl Med (2015) 13:272. doi:10.1186/ s12967-015-0565-2

7. Khan MA, Maasch C, Vater A, Klussmann S, Morser J, Leung LL, et al. Targeting complement component 5 a promotes vascular integrity and limits airway remodeling. Proc Natl Acad Sci U S A (2013) 110:6061-6. doi:10.1073/ pnas. 1217991110

8. Khan MA, Nicolls MR. Complement-mediated microvascular injury leads to chronic rejection. Adv Exp Med Biol (2013) 734:233-46. doi:10.1007/9781-4614-4118-2_16

9. Khan MA, Nicolls MR, Surguladze B, Saadoun I. Complement components as potential therapeutic targets for asthma treatment. Respir Med (2014) 108:543-9. doi:10.1016/j.rmed.2014.01.005

10. Strainic MG, Liu J, Huang D, An F, Lalli PN, Muqim N, et al. Locally produced complement fragments $\mathrm{C} 5 \mathrm{a}$ and $\mathrm{C} 3 \mathrm{a}$ provide both costimulatory and survival signals to naive CD4+ T cells. Immunity (2008) 28:425-35. doi:10.1016/j. immuni.2008.02.001

11. Kwan WH, van der Touw W, Paz-Artal E, Li MO, Heeger PS. Signaling through C5a receptor and C3a receptor diminishes function of murine natural regulatory T cells. J Exp Med (2013) 210:257-68. doi:10.1084/jem.20121525

12. Markiewski MM, Lambris JD. The role of complement in inflammatory diseases from behind the scenes into the spotlight. Am J Pathol (2007) 171:715-27. doi:10.2353/ajpath.2007.070166

13. Khan MA, Hsu JL, Assiri AM, Broering DC. Targeted complement inhibition and microvasculature in transplants: a therapeutic perspective. Clin Exp Immunol (2015) 183:175-86. doi:10.1111/cei.12713

14. Pierini A, Nishikii H, Baker J, Kimura T, Kwon H-S, Pan Y, et al. Foxp3+ regulatory $\mathrm{T}$ cells maintain the bone marrow microenvironment for $\mathrm{B}$ cell lymphopoiesis. Nat Commun (2017) 8:15068. doi:10.1038/ncomms 15068

15. Chatenoud L. Natural and induced T CD4+CD25+FOXP3+ regulatory T cells. In: Cuturi MC, Anegon I, editors. Suppression and Regulation of Immune Responses: Methods and Protocols. Totowa, NJ: Humana Press (2011). p. 3-13.

16. Kim JM, Rasmussen JP, Rudensky AY. Regulatory T cells prevent catastrophic autoimmunity throughout the lifespan of mice. Nat Immunol (2007) 8:191-7. doi:10.1038/ni1428

17. Sakaguchi S, Sakaguchi N, Shimizu J, Yamazaki S, Sakihama T, Itoh $\mathrm{M}$, et al. Immunologic tolerance maintained by $\mathrm{CD} 25+\mathrm{CD} 4+$ regulatory $\mathrm{T}$ cells: their common role in controlling autoimmunity, tumor
Riyadh, Kingdom of Saudi Arabia. We gratefully acknowledge our technical staff and purchasing system for prioritizing all research logistics in a timely fashion.

\section{FUNDING}

This study was supported by the King Faisal Specialist Hospital and Research Centre Kingdom of Saudi Arabia, under the RAC 2150017.

immunity, and transplantation tolerance. Immunol Rev (2001) 182:18-32. doi:10.1034/j.1600-065X.2001.1820102.x

18. Bharat A, Fields RC, Steward N, Trulock EP, Patterson GA, Mohanakumar T. CD4+25+ regulatory $\mathrm{T}$ cells limit Th1-autoimmunity by inducing IL-10 producing $\mathrm{T}$ cells following human lung transplantation. Am J Transplant (2006) 6:1799-808. doi:10.1111/j.1600-6143.2006.01383.x

19. Bilate AM, Lafaille JJ. Induced CD4+Foxp3+ regulatory T cells in immune tolerance. Annu Rev Immunol (2012) 30:733-58. doi:10.1146/annurevimmunol-020711-075043

20. Chesneau M, Michel L, Degauque N, Brouard S. Regulatory B cells and tolerance in transplantation: from animal models to human. Front Immunol (2013) 4:497. doi:10.3389/fimmu.2013.00497

21. Colonna L, Sega EI, Negrin RS. Natural and expanded CD4(+)CD25(+) regulatory T cells in bone marrow transplantation. Biol Blood Marrow Transplant (2011) 17:S58-62. doi:10.1016/j.bbmt.2010.10.020

22. Mathew JM, Voss JH, McEwen ST, Konieczna I, Chakraborty A, Huang X, et al. Generation and characterization of alloantigen-specific regulatory $\mathrm{T}$ cells for clinical transplant tolerance. Sci Rep (2018) 8(1):1136. doi:10.1038/ s41598-018-19621-6

23. Khan MA. T regulatory cell mediated immunotherapy for solid organ transplantation: A clinical perspective. Mol Med (2016) 22:892-904. doi:10.2119/ molmed.2016.00050

24. Khan MA, Alanazi F, Ahmed HA, Al-Mohanna FH, Assiri AM, Broering DC. FOXP3+ regulatory $\mathrm{T}$ cell ameliorates microvasculature in the rejection of mouse orthotopic tracheal transplants. Clin Immunol (2017) 174:84-98. doi:10.1016/j.clim.2016.11.011

25. Sakaguchi S. Regulatory T cells: key controllers of immunologic self-tolerance. Cell (2000) 101:455-8. doi:10.1016/S0092-8674(00)80856-9

26. Tang Q, Bluestone JA, Kang SM. CD4(+)Foxp3(+) regulatory T cell therapy in transplantation. J Mol Cell Biol (2012) 4:11-21. doi:10.1093/jmcb/ mjr047

27. Khan MA, Alanazi F, Ahmed HA, Hasan AF, Altuhami A, Assiri AM, et al. The therapeutic potential of Treg cells in preserving microvascular health in a mouse model of orthotopic tracheal transplantation. J Clin Cell Immunol (2016) 7:89. doi:10.4172/2155-9899.C1.028

28. Horch M, Nguyen VH. Regulatory T-cell immunotherapy for allogeneic hematopoietic stem-cell transplantation. Ther Adv Hematol (2012) 3:29-44. doi:10.1177/2040620711422266

29. Zouggari Y, Ait-Oufella H, Waeckel L, Vilar J, Loinard C, Cochain C, et al. Regulatory $\mathrm{T}$ cells modulate postischemic neovascularization. Circulation (2009) 120:1415-25. doi:10.1161/CIRCULATIONAHA.109.875583

30. Chatila TA. Role of regulatory $\mathrm{T}$ cells in human diseases. JAllergy Clin Immunol (2005) 116:949-59. doi:10.1016/j.jaci.2005.08.047

31. Di Ianni M, Falzetti F, Carotti A, Terenzi A, Castellino F, Bonifacio E, et al. Tregs prevent GVHD and promote immune reconstitution in HLA-haploidentical transplantation. Blood (2011) 117:3921-8. doi:10.1182/blood-2010-10-311894

32. Fehervari Z, Sakaguchi S. CD4+ Tregs and immune control. J Clin Invest (2004) 114:1209-17. doi:10.1172/JCI200423395

33. Ge W, Jiang J, Arp J, Liu W, Garcia B, Wang H. Regulatory T-cell generation and kidney allograft tolerance induced by mesenchymal stem cells associated with indoleamine 2,3-dioxygenase expression. Transplantation (2010) 90: 1312-20. doi:10.1097/TP.0b013e3181fed001

34. Ge W, Jiang J, Liu W, Lian D, Saito A, Garcia B, et al. Regulatory T cells are critical to tolerance induction in presensitized mouse transplant recipients through targeting memory T cells. Am J Transplant (2010) 10:1760-73. doi:10.1111/j.1600-6143.2010.03186.x 
35. Issa $\mathrm{F}$, Wood $\mathrm{KJ}$. CD4+ regulatory $\mathrm{T}$ cells in solid organ transplantation. Curr Opin Organ Transplant (2010) 15:757-64. doi:10.1097/MOT. ob013e32834017ae

36. Wolf D, Schreiber TH, Tryphonopoulos P, Li S, Tzakis AG, Ruiz P, et al. Tregs expanded in vivo by TNFRSF25 agonists promote cardiac allograft survival. Transplantation (2012) 94:569-74. doi:10.1097/TP.0b013e318264d3ef

37. Khan MA, Moeez S, Akhtar S. T-regulatory cell-mediated immune tolerance as a potential immunotherapeutic strategy to facilitate graft survival. Blood Transfus (2013) 11:357-63. doi:10.2450/2013.0258-12

38. Lalli PN, Strainic MG, Yang M, Lin F, Medof ME, Heeger PS. Locally produced C5a binds to $\mathrm{T}$ cell-expressed C5aR to enhance effector T-cell expansion by limiting antigen-induced apoptosis. Blood (2008) 112:1759-66. doi:10.1182/ blood-2008-04-151068

39. Gueler F, Rong S, Gwinner W, Mengel M, Bröcker V, Schön S, et al. Complement 5a receptor inhibition improves renal allograft survival. J Am Soc Nephrol (2008) 19:2302-12. doi:10.1681/ASN.2007111267

40. Cravedi P, Heeger PS. Complement as a multifaceted modulator of kidney transplant injury. J Clin Invest (2014) 124:2348-54. doi:10.1172/JCI72273

41. Cravedi P, Leventhal J, Lakhani P, Ward SC, Donovan MJ, Heeger PS. Immune cell-derived C3a and C5a costimulate human T cell alloimmunity. Am J Transplant (2013) 13:2530-9. doi:10.1111/ajt.12405

42. Wang Y, Lai P, Chen X, He C, Huang X, Geng S, et al. Attenuation of cGVHD by C5a/C5aR blockade is associated with increased frequency of Treg. Sci Rep (2017) 7:3603. doi:10.1038/s41598-017-03700-1

43. Khan MA, Dhillon G, Jiang X, Lin YC, Nicolls MR. New methods for monitoring dynamic airway tissue oxygenation and perfusion in experimental and clinical transplantation. Am J Physiol Lung Cell Mol Physiol (2012) 303(10):L861-9. doi:10.1152/ajplung.00162.2012

44. Babu AN, Murakawa T, Thurman JM, Miller EJ, Henson PM, Zamora MR, et al. Microvascular destruction identifies murine allografts that cannot be rescued from airway fibrosis. J Clin Invest (2007) 117:3774-85. doi:10.1172/ JCI32311

45. Jiang X, Khan MA, Tian W, Beilke J, Natarajan R, Kosek J, et al. Adenovirusmediated HIF-1alpha gene transfer promotes repair of mouse airway allograft microvasculature and attenuates chronic rejection. JClin Invest (2011) 121:2336-49. doi:10.1172/JCI46192

46. Khan MA, Jiang X, Dhillon G, Beilke J, Holers VM, Atkinson C, et al. CD4+ $\mathrm{T}$ cells and complement independently mediate graft ischemia in the rejection of mouse orthotopic tracheal transplants. Circ Res (2011) 109:1290-301. doi:10.1161/CIRCRESAHA.111.250167

47. Lama VN, Belperio JA, Christie JD, El-Chemaly S, Fishbein MC, Gelman AE, et al. Models of lung transplant research: a consensus statement from the national heart, lung, and blood institute workshop. JCI Insight (2017) 2:1-14. doi:10.1172/jci.insight.93121

48. Hsu JL, Khan MA, Sobel RA, Jiang X, Clemons KV, Nguyen TT, et al. Aspergillus fumigatus invasion increases with progressive airway ischemia. PLoS One (2013) 8:e77136. doi:10.1371/journal.pone.0077136

49. Li W, Carper K, Liang Y, Zheng XX, Kuhr CS, Reyes JD, et al. Anti-CD25 mAb administration prevents spontaneous liver transplant tolerance. Transplant Proc (2006) 38:3207-8. doi:10.1016/j.transproceed.2006.10.094

50. Ajona D, Ortiz-Espinosa S, Moreno H, Lozano T, Pajares MJ, Agorreta J, et al. A combined PD-1/C5a blockade synergistically protects against lung cancer growth and metastasis. Cancer Discov (2017) 7(7):694-703. doi:10.1158/21598290.CD-16-1184

51. Klussmann S, Nolte A, Bald R, Erdmann VA, Furste JP. Mirror-image RNA that binds D-adenosine. Nat Biotechnol (1996) 14:1112-5. doi:10.1038/ nbt0996-1112

52. Bain B, Pshyk K. Enhanced reactivity in mixed leukocyte cultures after separation of mononuclear cells on Ficoll-Hypaque. Transplant Proc (1972) 4:163-4.

53. Swaisgood CM, French EL, Noga C, Simon RH, Ploplis VA. The development of bleomycin-induced pulmonary fibrosis in mice deficient for components of the fibrinolytic system. Am J Pathol (2000) 157:177-87. doi:10.1016/ S0002-9440(10)64529-4

54. Reinhardt AK, Bottoms SE, Laurent GJ, McAnulty RJ. Quantification of collagen and proteoglycan deposition in a murine model of airway remodelling. Respir Res (2005) 6:30. doi:10.1186/1465-9921-6-30

55. Kuo E, Bharat A, Goers T, Chapman W, Yan L, Street T, et al. Respiratory viral infection in obliterative airway disease after orthotopic tracheal transplantation. Ann Thorac Surg (2006) 82:1043-50. doi:10.1016/j.athoracsur. 2006.03.120

56. van der Touw W, Cravedi P, Kwan W-h, Paz-Artal E, Merad M, Heeger PS. Receptors for C3a and C5a modulate stability of alloantigen-reactive induced regulatory T cells. JImmunol (2013) 190:5921-5. doi:10.4049/ jimmunol.1300847

57. Weaver DJ Jr, Reis ES, Pandey MK, Kohl G, Harris N, Gerard C, et al. C5a receptor-deficient dendritic cells promote induction of Treg and Th17 cells. Eur J Immunol (2010) 40:710-21. doi:10.1002/eji.200939333

58. Ender F, Wiese AV, Schmudde I, Sun J, Vollbrandt T, Konig P, et al. Differential regulation of $\mathrm{C} 5 \mathrm{a}$ receptor 1 in innate immune cells during the allergic asthma effector phase. PLoS One (2017) 12:e0172446. doi:10.1371/journal.pone. 0172446

59. Strainic MG, Shevach EM, An F, Lin F, Medof ME. Absence of signaling into $\mathrm{CD} 4(+)$ cells via C3aR and C5aR enables autoinductive TGF-betal signaling and induction of Foxp3(+) regulatory T cells. Nat Immunol (2013) 14:162-71. doi:10.1038/ni.2499

60. van der Net JB, Bushell A, Wood KJ, Harden PN. Regulatory T cells: first steps of clinical application in solid organ transplantation. Transpl Int (2016) 29:3-11. doi:10.1111/tri.12608

61. Tang Q, Kang SM. Interpretation of transplant biopsies and immune responses following Treg cell therapy. Curr Opin Organ Transplant (2014) 19:616-20. doi:10.1097/MOT.0000000000000132

62. Liu G, Ma H, Qiu L, Li L, Cao Y, Ma J, et al. Phenotypic and functional switch of macrophages induced by regulatory $\mathrm{CD} 4+\mathrm{CD} 25+\mathrm{T}$ cells in mice. Immunol Cell Biol (2011) 89:130-42. doi:10.1038/icb.2010.70

63. Yu X, Li H, Ren X. Interaction between regulatory $\mathrm{T}$ cells and cancer stem cells. Int J Cancer (2012) 131:1491-8. doi:10.1002/ijc.27634

64. Fontenot JD, Gavin MA, Rudensky AY. Foxp3 programs the development and function of CD4+CD25+ regulatory T cells. Nat Immunol (2003) 4:330-6. doi:10.1038/ni904

65. Hori S, Nomura T, Sakaguchi S. Control of regulatory T cell development by the transcription factor Foxp3. Science (2003) 299:1057-61. doi:10.1126/ science. 1079490

66. Khattri R, Cox T, Yasayko SA, Ramsdell F. An essential role for Scurfin in CD4+CD25+ T regulatory cells. Nat Immunol (2003) 4:337-42. doi:10.1038/ ni909

67. Lundgren A, Stromberg E, Sjoling A, Lindholm C, Enarsson K, Edebo A, et al. Mucosal FOXP3-expressing CD4+ CD25high regulatory T cells in Helicobacter pylori-infected patients. Infect Immun (2005) 73:523-31. doi:10.1128/ IAI.73.1.523-531.2005

68. Okazaki M, Gelman AE, Tietjens JR, Ibricevic A, Kornfeld CG, Huang HJ, et al. Maintenance of airway epithelium in acutely rejected orthotopic vascularized mouse lung transplants. Am J Respir Cell Mol Biol (2007) 37:625-30. doi:10.1165/rcmb.2007-0257RC

69. Smith CR, Jaramillo A, Duffy BF, Mohanakumar T. Airway epithelial cell damage mediated by antigen-specific $\mathrm{T}$ cells: implications in lung allograft rejection. Hum Immunol (2000) 61:985-92. doi:10.1016/S0198-8859(00)00175-0

70. Lentsch $\mathrm{AB}$, Ward PA. Regulation of experimental lung inflammation. Respir Physiol (2001) 128:17-22. doi:10.1016/S0034-5687(01)00260-2

71. Fernandez FG, Jaramillo A, Chen C, Liu DZ, Tung T, Patterson GA, et al. Airway epithelium is the primary target of allograft rejection in murine obliterative airway disease. Am J Transplant (2004) 4:319-25. doi:10.1111/j.1600-6143. 2004.00333.x

72. Barnett AN, Asgari E, Chowdhury P, Sacks SH, Dorling A, Mamode N. The use of eculizumab in renal transplantation. Clin Transplant (2013) 27:E216-29. doi:10.1111/ctr.12102

73. Ma Q, Li D, Carreno R, Patenia R, Tsai KY, Xydes-Smith M, et al. Complement component C3 mediates Th1/Th17 polarization in human T-cell activation and cutaneous GVHD. Bone Marrow Transplant (2014) 49:972-6. doi:10.1038/ bmt. 2014.75

74. Chen G, Yang Y, Gao X, Dou Y, Wang H, Han G, et al. Blockade of complement activation product $\mathrm{C} 5 \mathrm{a}$ activity using specific antibody attenuates intestinal damage in trinitrobenzene sulfonic acid induced model of colitis. Lab Invest (2011) 91:472-83. doi:10.1038/labinvest.2010.183

Conflict of Interest Statement: AV is co-inventor of AON-D21 and has co-founded APTARION biotech AG, which holds intellectual property rights on 
this substance and its use. Author AV is shareholder and employee of Aptarion biotech AG, Germany, which holds intellectual property rights on the C5aneutralizing L-aptamer used in this study, and is co-inventor of this substance. All authors declare that they have no competing interests as defined by Journal, or other interests that might be perceived to influence the results and discussion reported in this paper.
Copyright (c) 2018 Khan, Alanazi, Ahmed, Vater, Assiri and Broering. This is an open-access article distributed under the terms of the Creative Commons Attribution License (CC BY). The use, distribution or reproduction in other forums is permitted, provided the original author(s) and the copyright owner are credited and that the original publication in this journal is cited, in accordance with accepted academic practice. No use, distribution or reproduction is permitted which does not comply with these terms. 